دراسة اقتصادية لأمماط الإفاق الاستهلاكى الفردى على المجموعات الغذائية المختلفة فى ريف وحضر مصر الفرد علئر

مصطفي حسن مصطفي محمد ، ياسر عبد الحميد دياب وداليا حامد الثويخ وفريخ

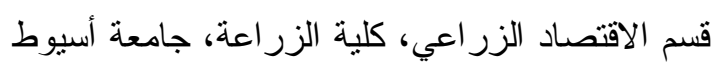

Received on: 25/9/2019

Accepted for publication on: 30/10/2019

(المقدمة

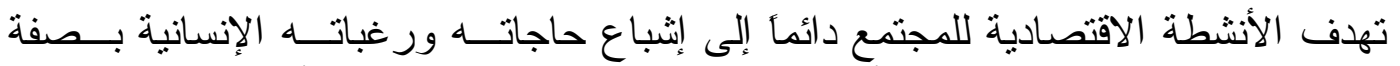

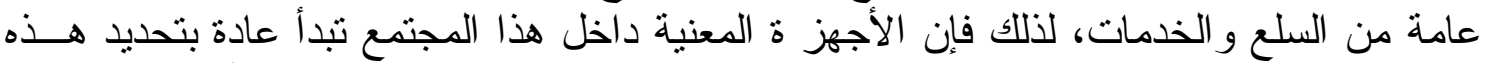

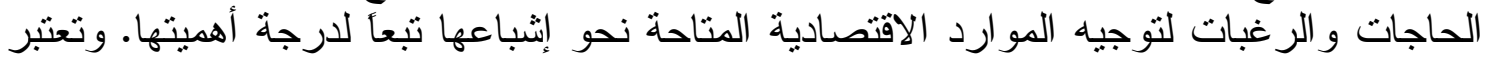

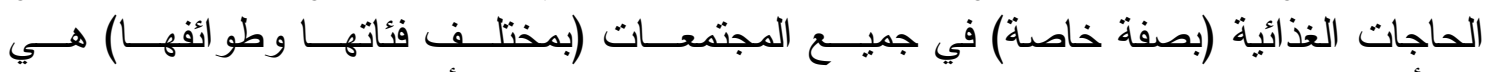

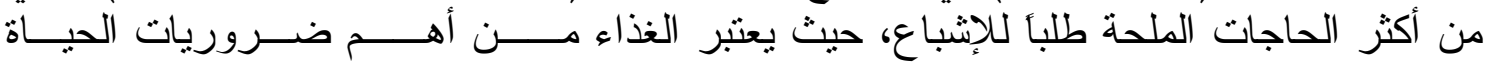

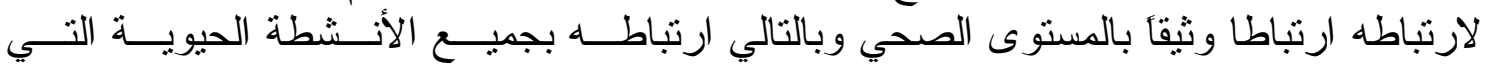

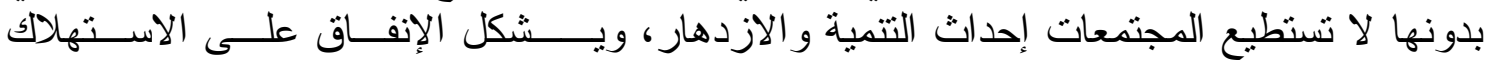

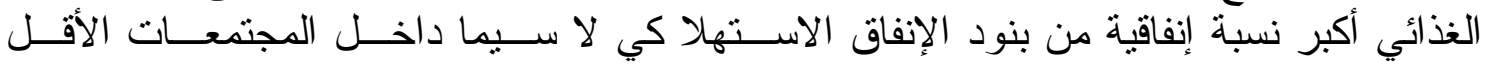

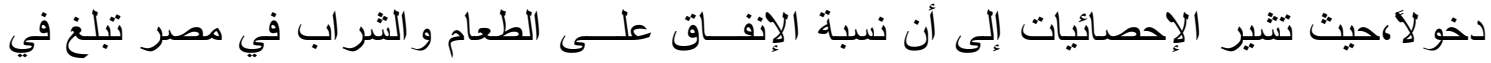

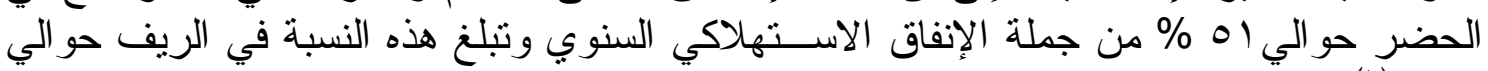
(1)\%०。.

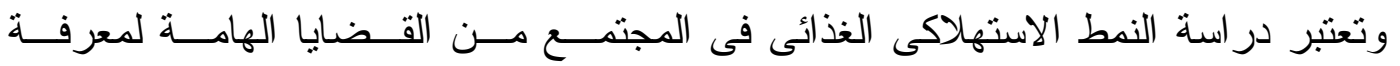

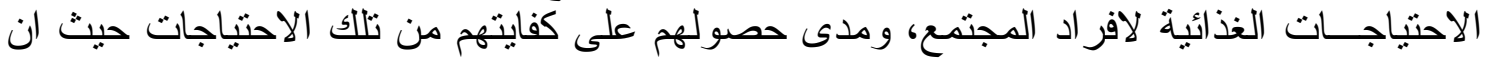

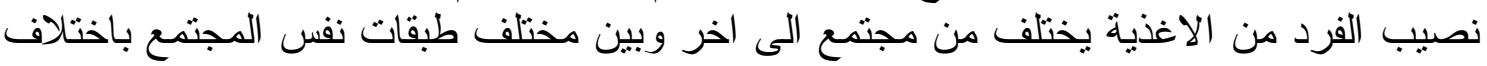

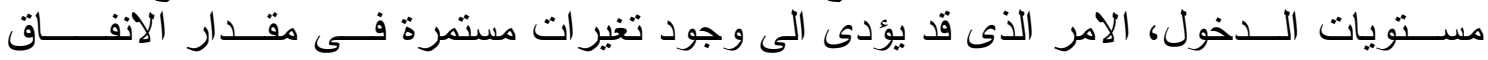

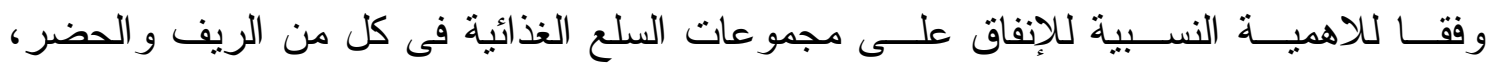

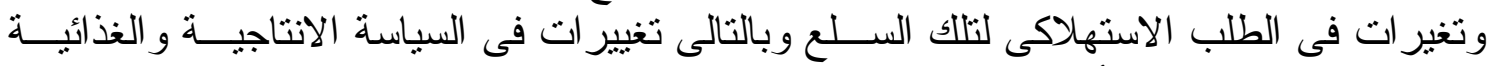

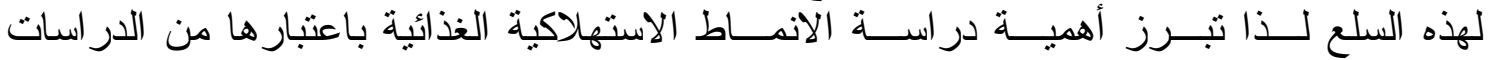

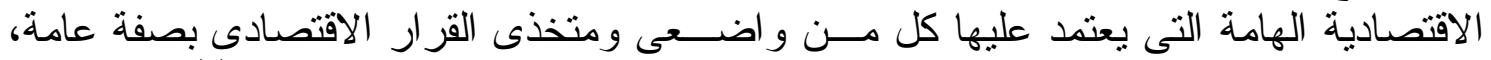

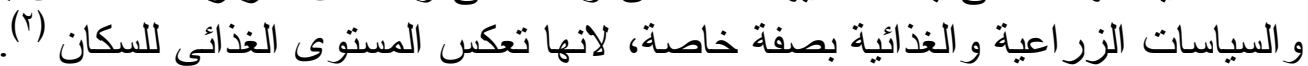
مشكلة البحث

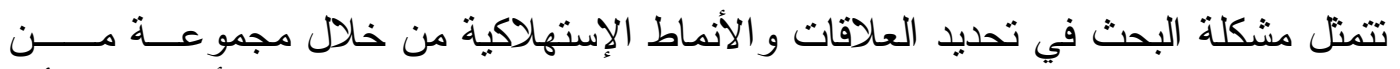

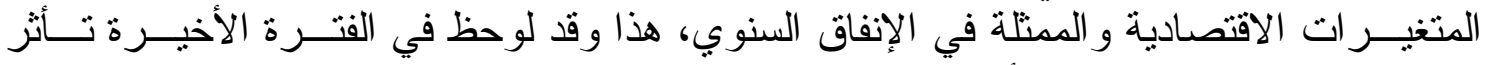

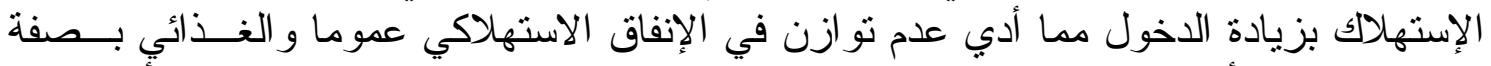

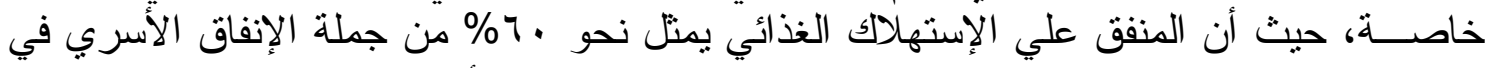

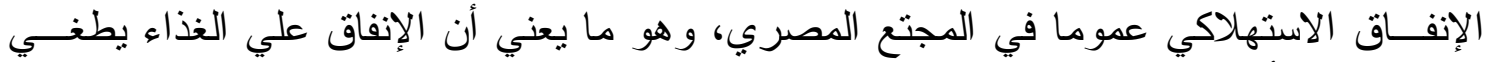

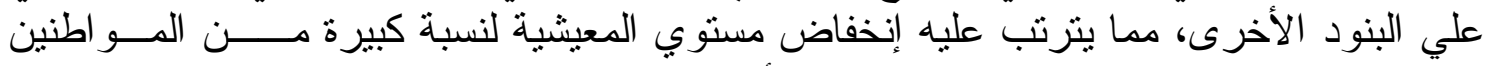

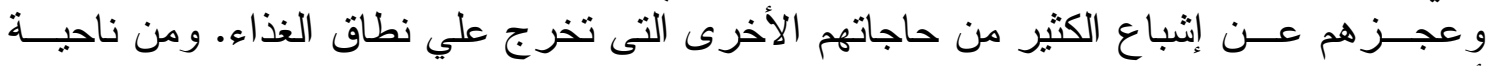

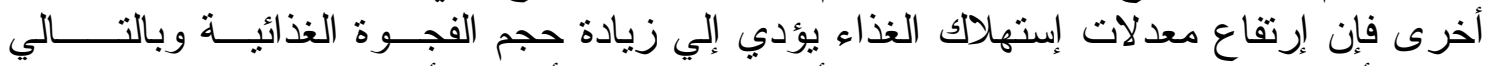

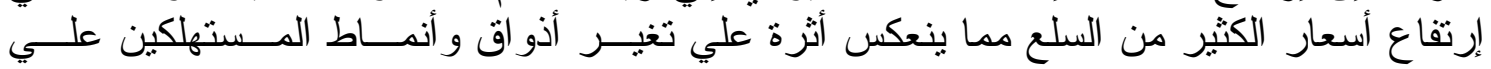

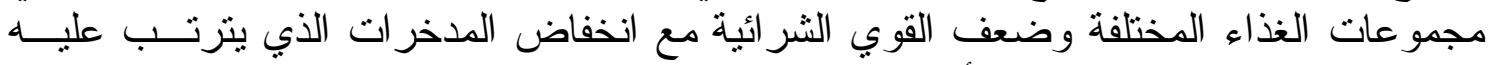
إسنتز اف الجهود المبذولة لتحقيق أهداف التتمية الاقتصادية و الاجتماعية المتو اصلة. 


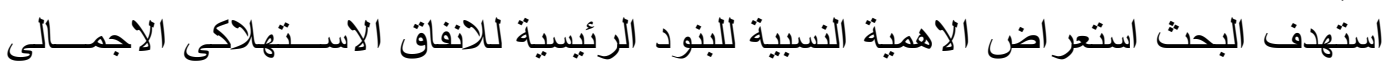

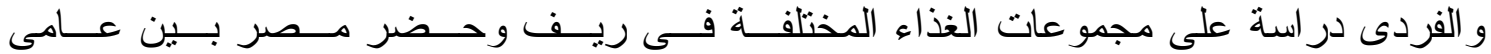

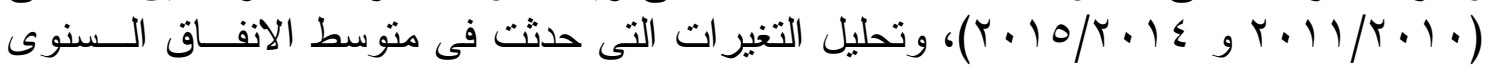

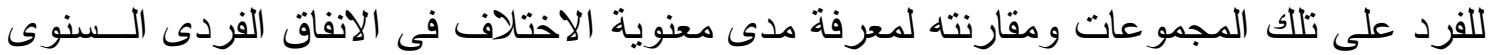

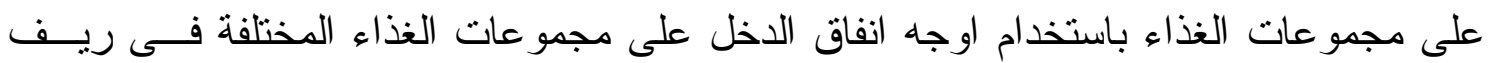

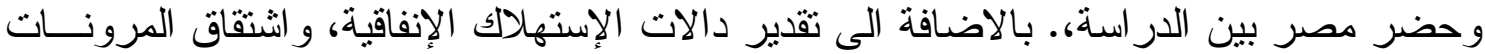

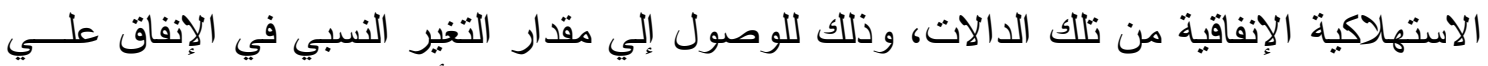

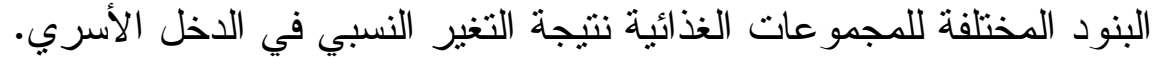
الطريقة البحثية ومصادر البيانات البذة البذات

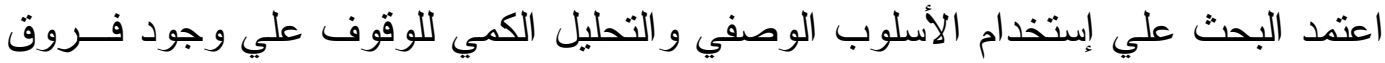

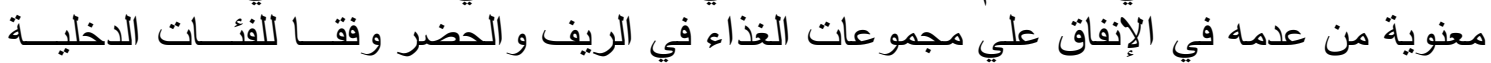

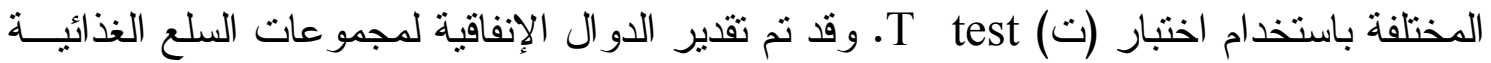

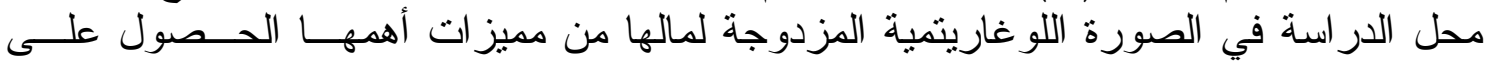

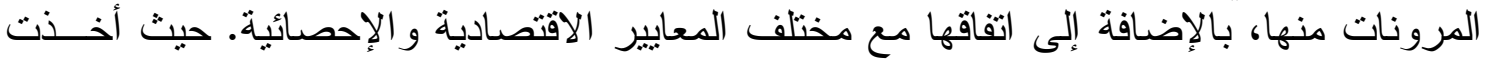

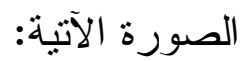

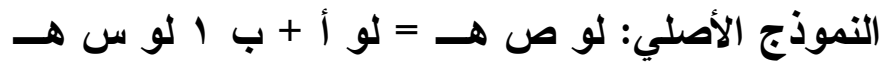

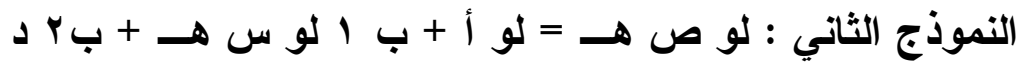

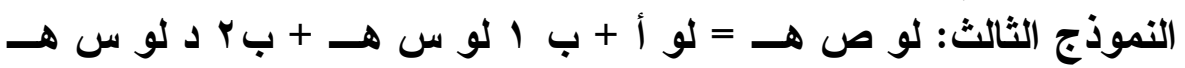
حيث : إن: لو ص هـ : لو غاريتم متوسط الإنفاق الفردي السنوي بالجنيه على المجموعة الغذائية. لو س هـ : لو غاريتم اجمالي الإنفاق الاستهلاكي الفردي السنوي الإنفافي بالجنيه.

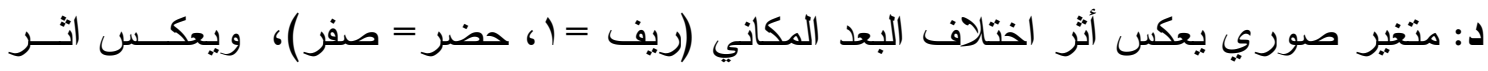

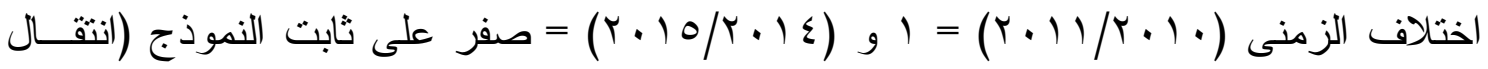

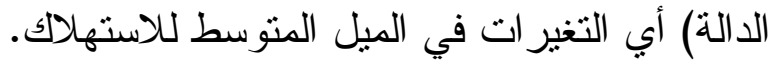

أ: ثابت الدالة الإنفاقية ب: المرونة الإنفاقية للمجموعة الغذائية. هـ : فئات الإنفاق المختلفة.

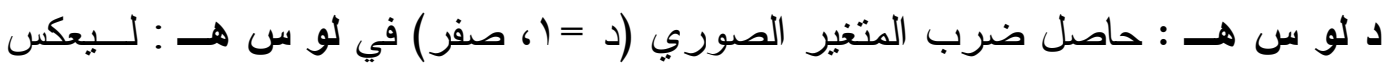

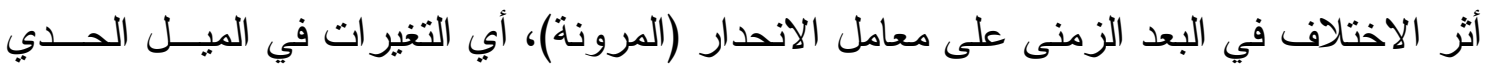
لكاستهلاك.

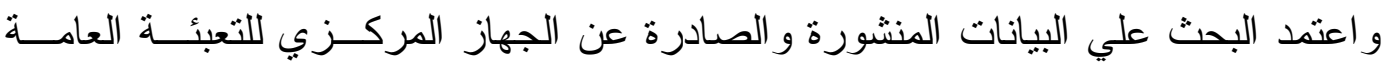

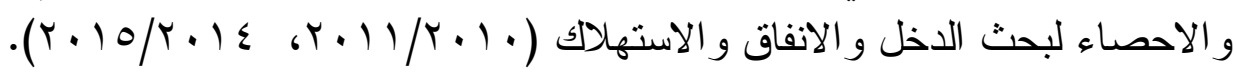

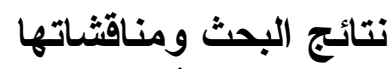
اولاً : تحليل أنماط الإنفاق الإستهلاكي الغذائي الفردى:

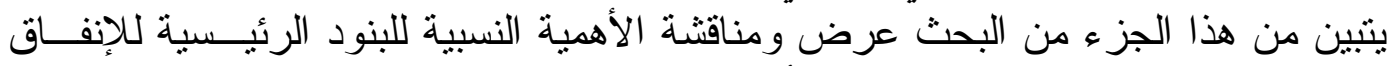

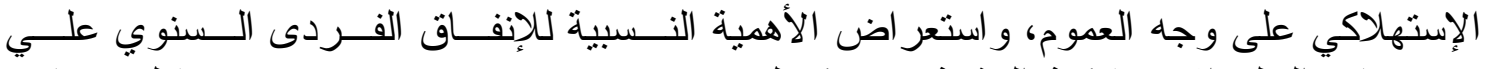

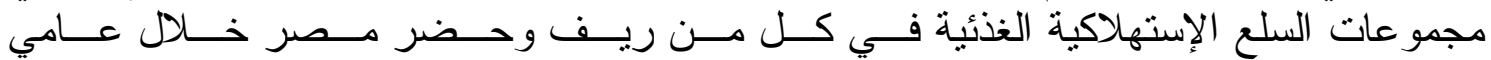

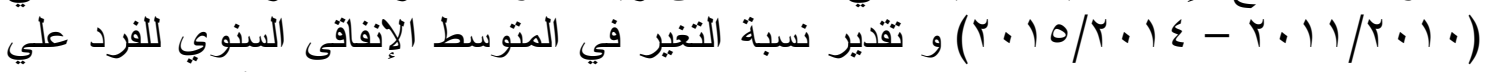

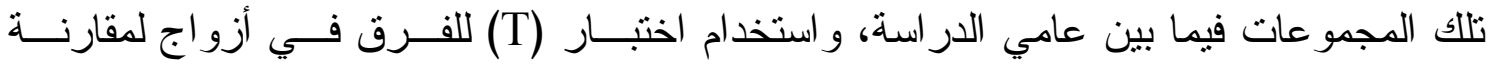




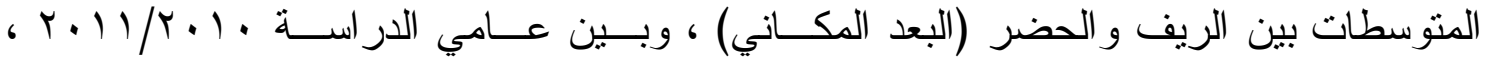

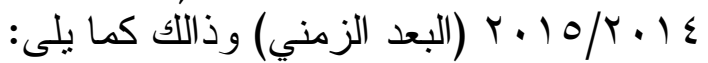

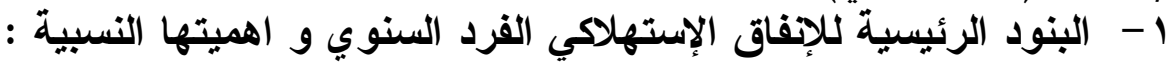

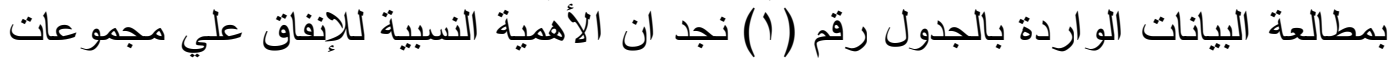

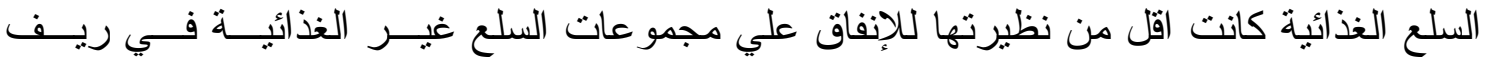

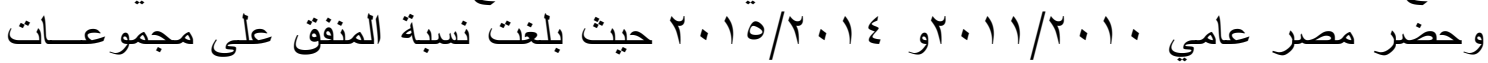

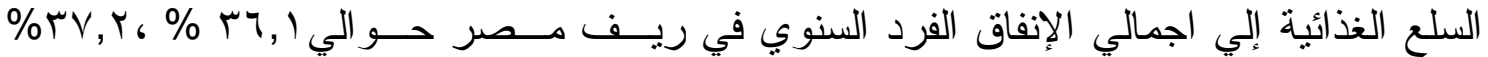

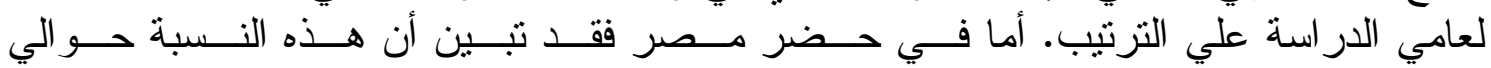

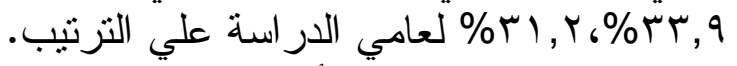

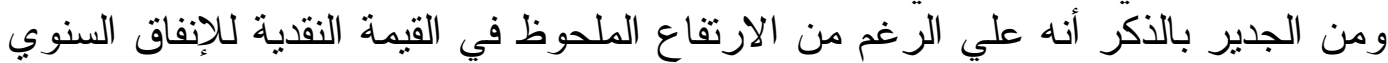

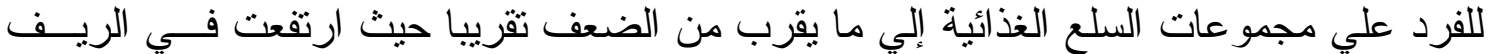

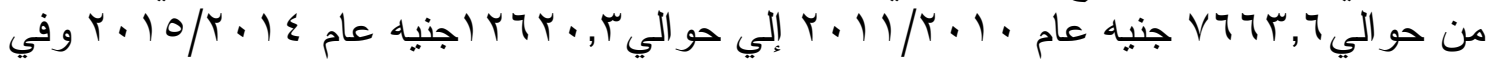

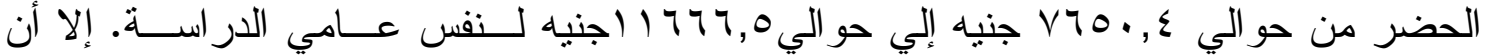

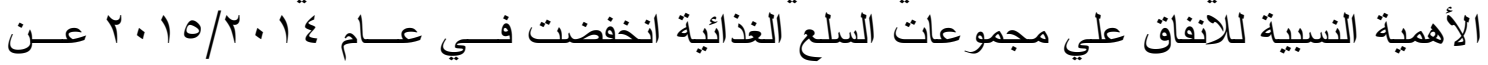

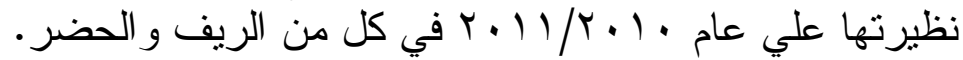

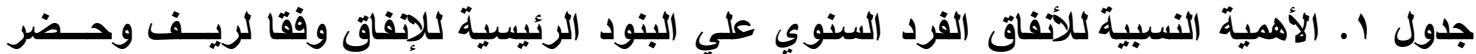

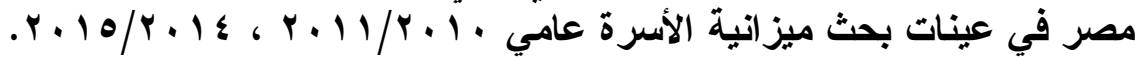

\begin{tabular}{|c|c|c|c|c|c|c|c|c|}
\hline \multicolumn{2}{|c|}{ حضر ( حضر } & \multicolumn{2}{|c|}{ حضر } & \multicolumn{2}{|c|}{ ريف } & \multicolumn{2}{|c|}{ ريف } & \multirow{3}{*}{ بنود أوجه الانفاق الاستهلاكي } \\
\hline \multicolumn{2}{|c|}{$r+10 / Y \cdot 1 \varepsilon$} & \multicolumn{2}{|c|}{$r \cdot 11 / r+1 \cdot$} & \multicolumn{2}{|c|}{$r+10 / r+1 \leq$} & \multicolumn{2}{|c|}{$r+11 / r+1}$. & \\
\hline$\%$ & قيمة & $\%$ & قيمة & $\%$ & قيمة & $\%$ & قيمة & \\
\hline rI.r & 11777.0 & rr.q & $V 70 . . \varepsilon$ & TV.Y & IYTY. & M. 1 & V74r. & اجمالي السلحع الغذائية \\
\hline 71.1 & roV/7.T & 77.1 & $1 \leqslant \wedge \wedge 9.0$ & TY.A & rITro.9 & 74.9 & 1roor.9 & اجمالي السلع غير الغذائية \\
\hline $1 \cdots \cdot$ & rVTAT. & $1 \cdots \cdot$ & rrorq. 9 & $1 \cdots \cdot$ & rr907.Y & $1 \cdots \cdot$ & YIYIT.E & اجمالي الانفاق الاستهلاكي \\
\hline
\end{tabular}

$(T \cdot 10 / \% \cdot 1 \varepsilon)(T \cdot 11 / \% \cdot 1 \cdot)$

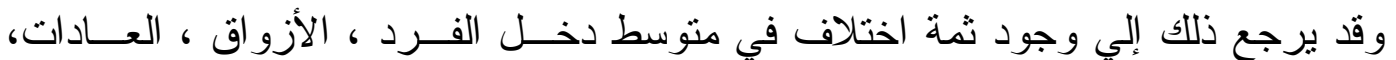

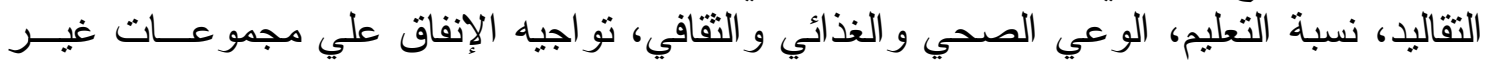

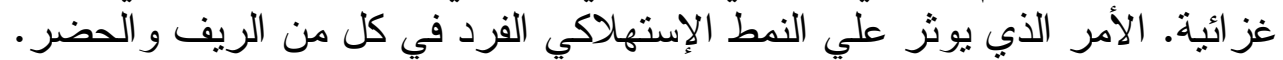

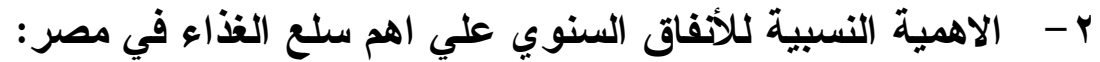

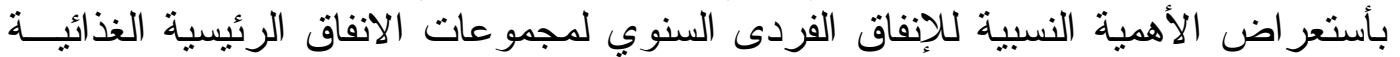

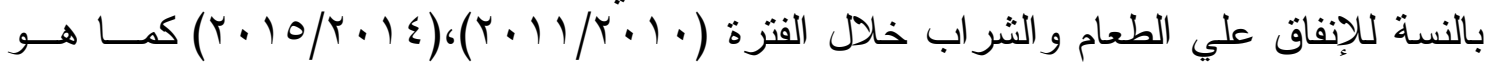

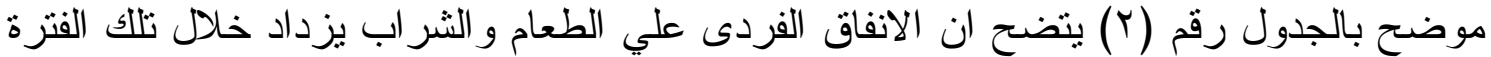

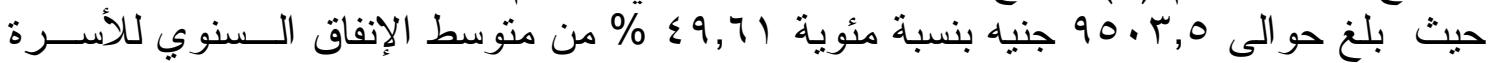

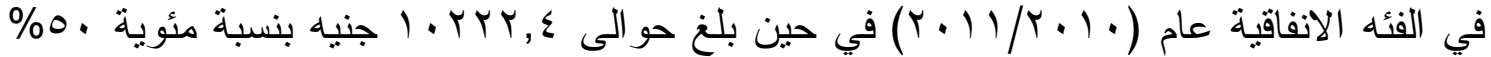

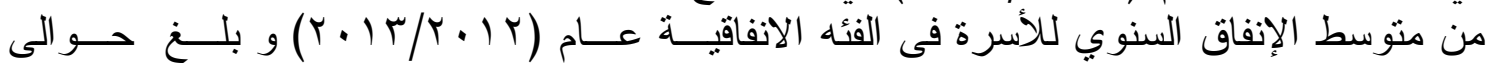

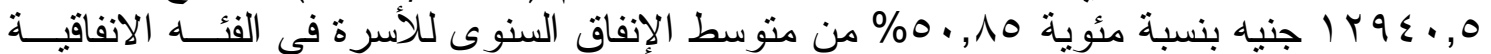

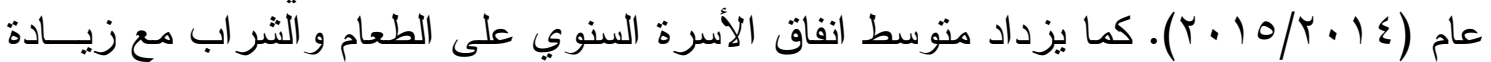

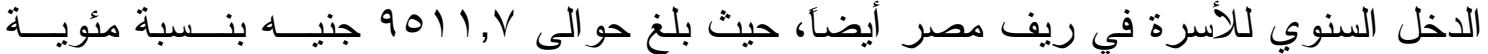

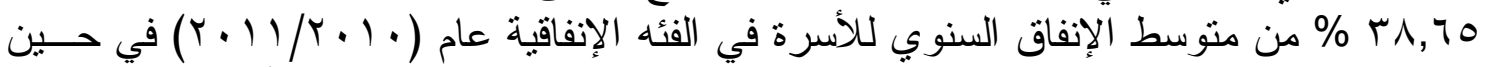

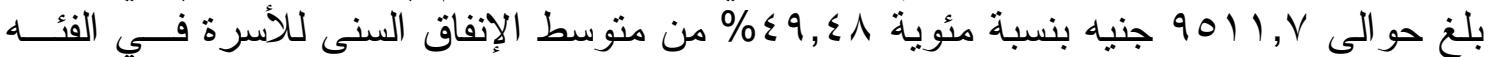

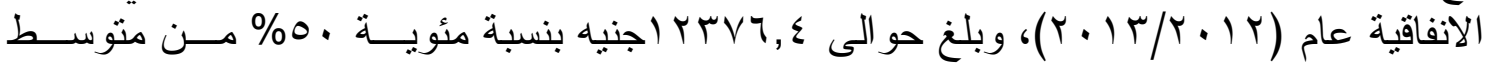

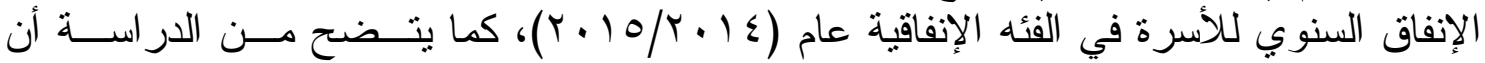


الإنفاق الفرد علي مجموعة اللحوم و الدو اجن بأتي في مقدمة الإنفاق علي المجموعات الغذائيــة

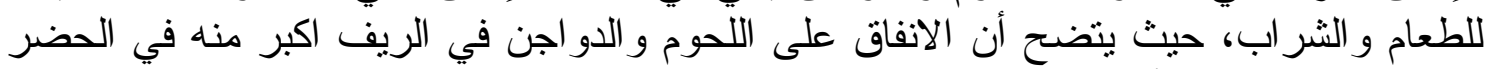

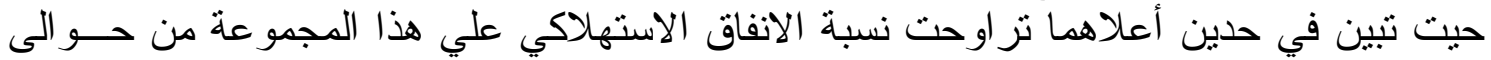

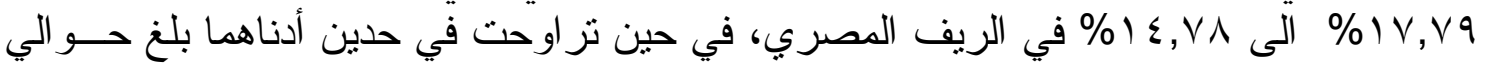

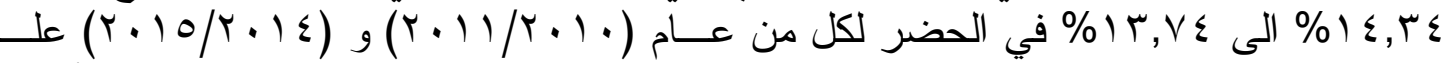

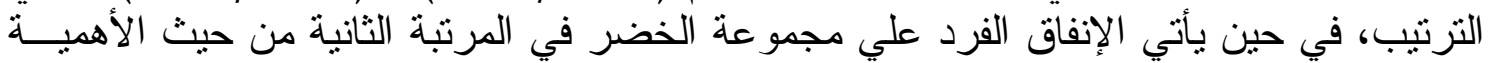

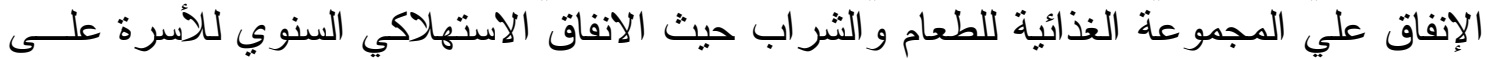

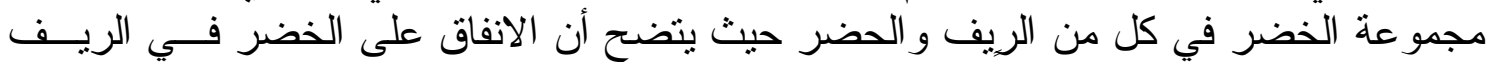

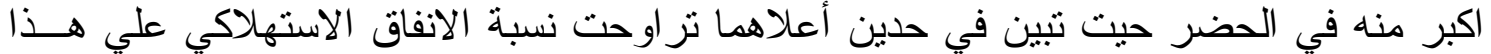

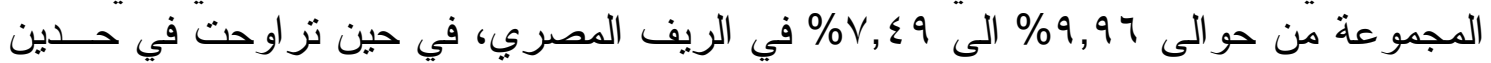

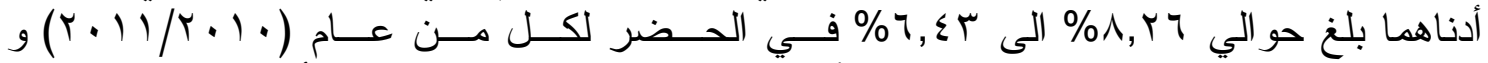

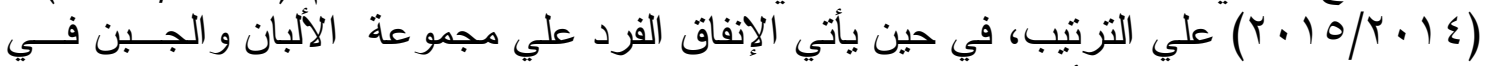

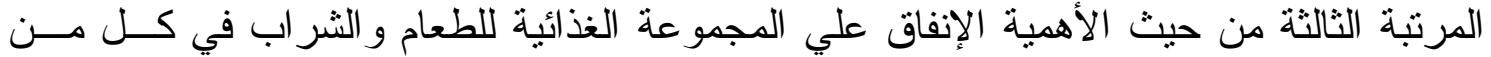

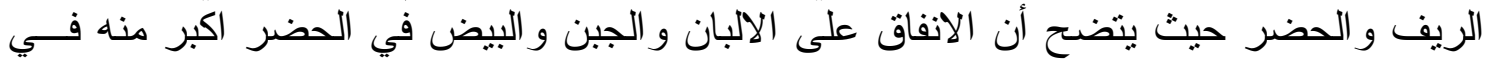

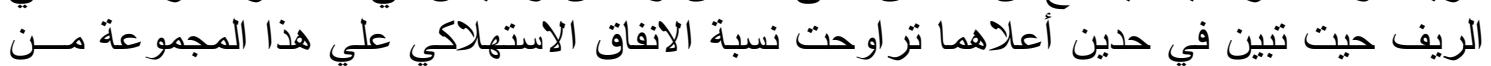

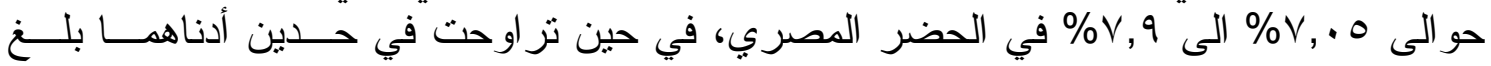

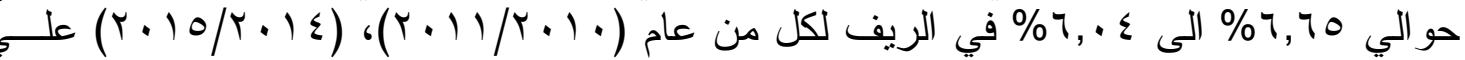

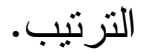
جدول ب. الأهمية النسبية للأفاق الفرد السنوي لمجموعات الإنفاق الرئيسية الغذائية بالنسبة للانفاق

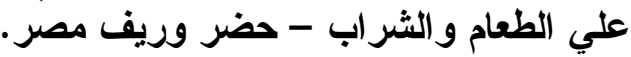

\begin{tabular}{|c|c|c|c|c|c|c|c|c|}
\hline \multicolumn{4}{|c|}{$r \cdot 10-r \cdot 1 \varepsilon$} & \multicolumn{4}{|c|}{$r \cdot 11-r \cdot 1}$. & \multirow{3}{*}{ المجموعات } \\
\hline \multicolumn{2}{|c|}{ ريف مصر } & \multicolumn{2}{|c|}{ حضر مصر } & \multicolumn{2}{|c|}{ ريف مصر } & \multicolumn{2}{|c|}{ حضر مصر } & \\
\hline$\%$ & قيمة & $\%$ & قيمة & $\%$ & قيمة & $\%$ & قيمة & \\
\hline $0 . \cdots$ & IYMVT.\&. & $0 . .10$ & $1 \times 9 \varepsilon \cdot .0$ & rA.70 & or71.9. & $\{9.71$ & 90.1 .0 & الطعام والشراب \\
\hline $0 . \wedge \varepsilon$ & $1 \leq \leqslant 0.0$. & $0 . M r$ & $1100 \leqslant .7$ & 9.7. & $1 \% \cdot 7.0$. & 0.90 & $\Pi \varepsilon \varepsilon \cdot r$ & الحبوب والخبز \\
\hline $1 \Sigma . \vee \wedge$ & 1901.7. & IT.VE & $r \leq 97.1$ & 18.89 & $r \leqslant Y r_{.} .$. & I $\leqslant . T \leqslant$ & $r V \leqslant V . r$ & اللحوم والدواجن \\
\hline r. & V7V.9. & T.7ร & $9 Y 7.4$ & מ.ז. & $\leqslant 0 \wedge .$. & T.TY & 794.9 & الاسماك \\
\hline $7 . \cdot \varepsilon$ & $1 \leqslant 97.4$. & V.9. & $r .11 . r$ & 7.70 & $9.0 .$. & $V .0$ & $1+5 \leqslant 9.9$ & الالبان والجبن والبيض \\
\hline$\varepsilon .49$ & $1 \cdot \lambda v . \varepsilon \cdot$ & $r . \leqslant 0$ & 1Vq & $\leqslant .0 \leqslant$ & $71 V .0$. & T.Y & TYI & زيت والدهون \\
\hline$r .1 \varepsilon$ & $\vee \vee 7.9$. & r.r. & $1 r^{\circ} .0$ & $r .91$ & $0 \leqslant 1 . \Gamma$. & r.OV & TAr.r & الفاكهة \\
\hline$V . \varepsilon q$ & l10r.V. & $7 . \varepsilon r$ & $1747 . \mathrm{V}$ & 9.97 & 1507.0. & $\Lambda . Y 7$ & TONY.Y & خضر \\
\hline r.o. & $719 .$. & T.YO & OVT.Y & T.77 & rצr.r. & T.IT & $\varepsilon \cdot V$ & السكر والاغذية السكرية \\
\hline $1 . \cdot Y$ & Y01.E. & 1.1 & roY.ᄉ & $\because 9 V$ & 141.7. & $\because 9$ & IVY.Z & منتجات الاغذية الغير مصنعة \\
\hline 1.79 & $\lesssim \backslash \wedge . \wedge$. & r.l. & or $\leq \varepsilon$ & $1 . \wedge \varepsilon$ & ro.. ह. & $1 . \mu \varepsilon$ & YOY.Y & لمشروبات الغير كحولية \\
\hline $1 \ldots$ & $r \leqslant \vee 01 . \wedge$ & $1 \cdots$ & $r 0 \leqslant \leqslant \wedge .9$ & $1 \cdots$ & 1 & $1 \ldots$ & 19101 & جمالي الإنفاق الاستهلاكي \\
\hline
\end{tabular}

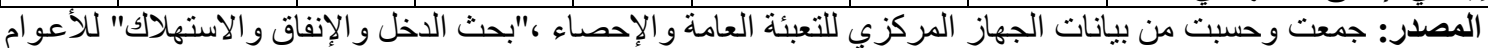

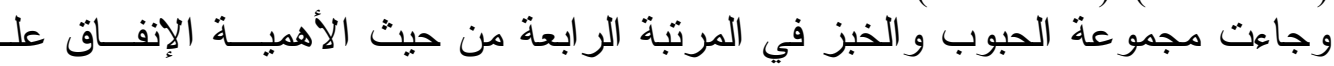

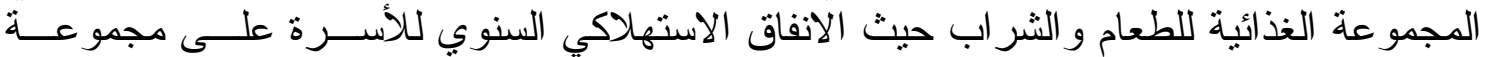

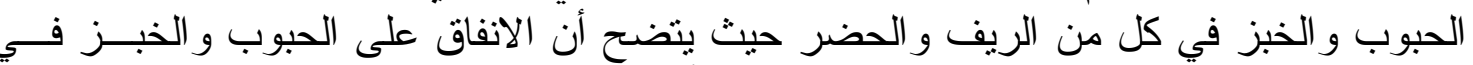

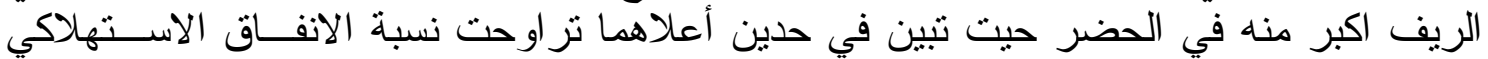

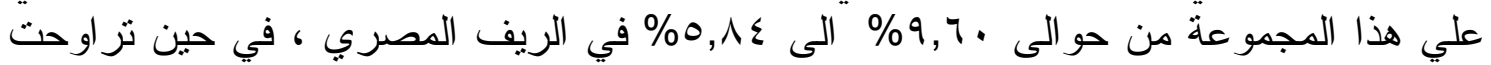

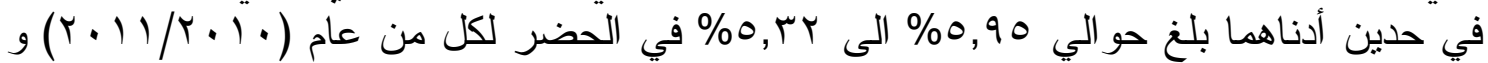

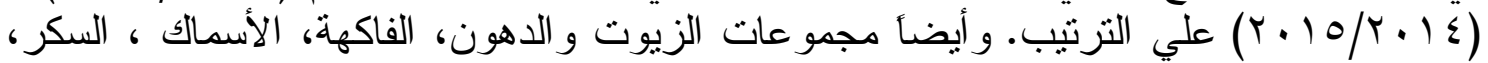

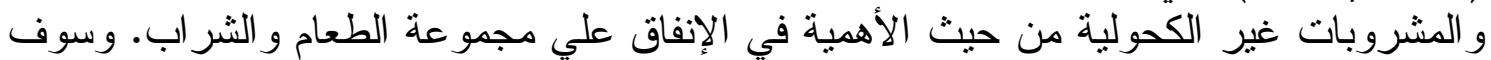
تقتصر الدر اسة علي مجموعات اللحوم ، و الخضر ، و الألبان و الجبن ، ولئ و الحبوب و والخبز . 
ب- التغير في الإنفاق السنوي للفرد علي المجموعات الغذائية المختلفة علــي مسـتصوي ريف وحضر مصر:

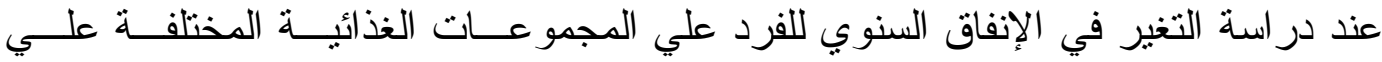

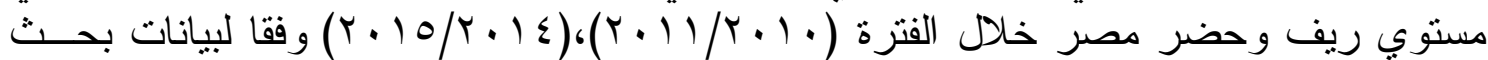

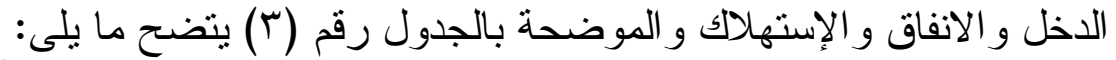

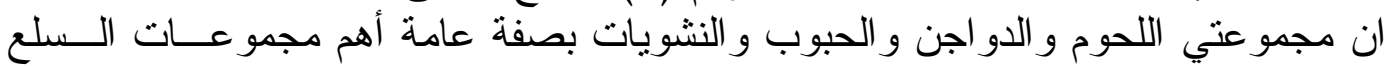

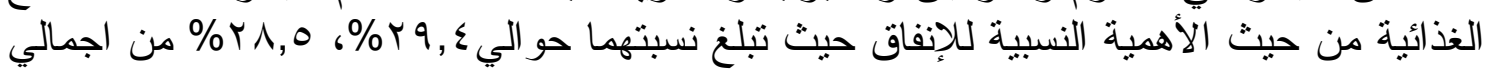

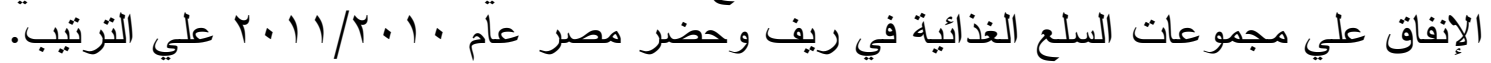

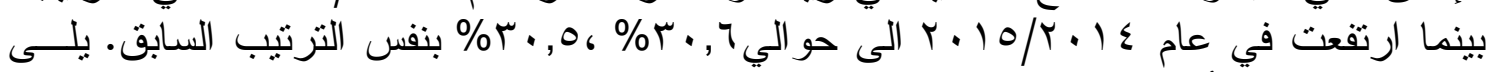

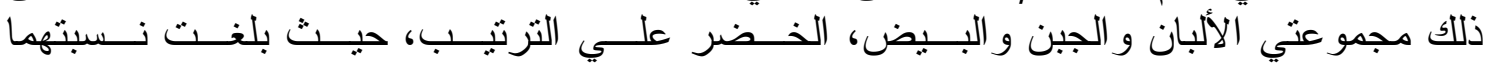

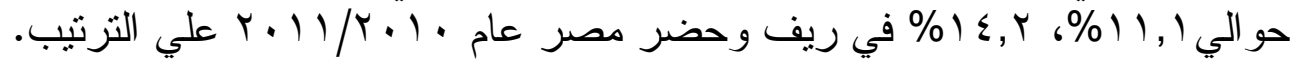

جدول r. التغير في المتوسط الإففاق السنوي للفرد والأهمية النسبية للمنفق علي مجموعات الغذائية

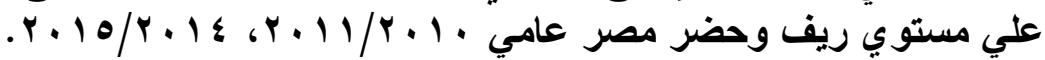

\begin{tabular}{|c|c|c|c|c|c|c|c|c|c|c|c|c|c|c|}
\hline \multirow{2}{*}{\multicolumn{2}{|c|}{ بين الفترتين الفرق }} & \multirow{2}{*}{\multicolumn{2}{|c|}{ بين الفترتين في الانفاق }} & \multicolumn{5}{|c|}{$r \cdot 10 / r \cdot 1 \varepsilon$} & \multicolumn{5}{|c|}{$r .11 / r .1}$. & \multirow[t]{2}{*}{ السنوات } \\
\hline & & & & \multirow{2}{*}{ الفرق } & \multicolumn{2}{|r|}{ حضر } & \multicolumn{2}{|r|}{ ريف } & \multirow{2}{*}{ | معنوية } & \multicolumn{2}{|c|}{ حضر } & \multicolumn{2}{|c|}{ ريف } & \\
\hline حضر & ريف & حضر & ريف & & $\%$ & المتوسط & $\%$ & المتوسط & & $\%$ & المتوسط & $\%$ & المتوسط & المجموعة الغذائية \\
\hline$(-)$ & $*$ & $(-)$ & $(-)$ & $* *$ & 9.9 & $110 \%$. & 11.5 & $1 \leq \Gamma \leq . T$ & $* *$ & Ir & $91 \wedge . \varepsilon$ & $10 . r$ & $11 V 1.0$ & الحبوب والخبز \\
\hline$* *$ & $* *$ & + & + & $* *$ & $r \cdot 0$ & 1000.1 & $r \cdot .7$ & 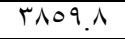 & $(-)$ & rA. 0 & YIVV. & rq. & rTOY.r & اللحوم \\
\hline ** & $* *$ & . & $\cdot$ & $(-)$ & V.Y & 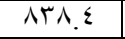 & 7.1 & VAr.r & $(-)$ & V.Y & $0 \leqslant \wedge . \varepsilon$ & 7.1 & $\varepsilon \wedge \varepsilon . \Gamma$ & الأسماك \\
\hline$* *$ & $* *$ & + & + & $* *$ & 10.9 & 1 110\%.0 & IT & $104 \cdot .7$ & $* *$ & $1 \leq . Y$ & $1 . \wedge r . \Lambda$ & 11.1 & $\wedge \leq q . V$ & الألبان - والجبن والبيض \\
\hline$* *$ & $* *$ & + & + & $* *$ & 7.0 & $V T \cdot r$ & 1.7 & I.AT.V & $* *$ & $7 . \varepsilon$ & $\varepsilon \wedge 9 . \mu$ & 1.0 & $7 \varepsilon \wedge$. & الزيوت و الدهون \\
\hline$* *$ & $* *$ & $(-)$ & + & $(-)$ & 7.0 & VTT.O & $7 . r$ & V99.V & $(-)$ & $\vee . \wedge$ & $09 \leq .9$ & 7. & 纟7T. & الفاكهة \\
\hline$* *$ & $* *$ & $(-)$ & + & $* *$ & Ir.A & $1 \leq 9 \leq . \wedge$ & $1 \leqslant . V$ & 1NOr.s & $(-)$ & $1 \leq$ & 1.71 .0 & $1 \leqslant .0$ & $111 Y . \Sigma$ & الخضر \\
\hline$* *$ & $* *$ & $(-)$ & + & $* *$ & $\varepsilon . \varepsilon$ & $011 . V$ & $\varepsilon . \wedge$ & 7.4 .9 & $(-)$ & $\varepsilon .7$ & $r \leq q$. & $\varepsilon . \varepsilon$ & rro.q & السكر والأغذية السكرية \\
\hline$* *$ & $* *$ & + & + & $(-)$ & $r$ & rTV.V & r & ro. . & $*$ & 1.1 & $11 \% 0.7$ & 1.0 & $11 \varepsilon . \varepsilon$ & منتجات الأغذية الغير مصنعة تحت بند إخر \\
\hline$* *$ & $* *$ & + & + & $(-)$ & $\varepsilon . Y$ & ह9!. & r.s & $\varepsilon r T_{.}$ & $(-)$ & r.V & 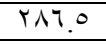 & r.e & KMI.I & المشروبات الغير كحولية \\
\hline$* *$ & $* *$ & + & + & $* *$ & $1 \cdots$ & 11777.0 & $1 \cdots$ & IYTY..T & $(-)$ & $1 \cdots$ & $170 . .5$ & $1 \cdots$ & Vエ7T. & اجمالي الطعام والثر اب \\
\hline
\end{tabular}

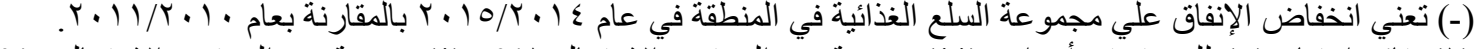

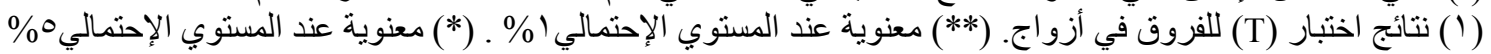

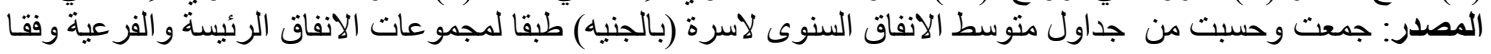

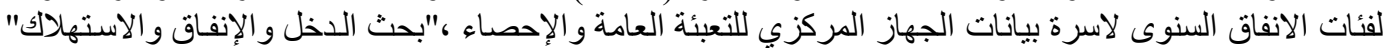

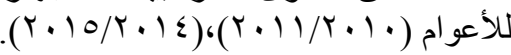

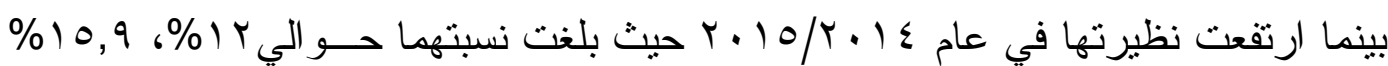

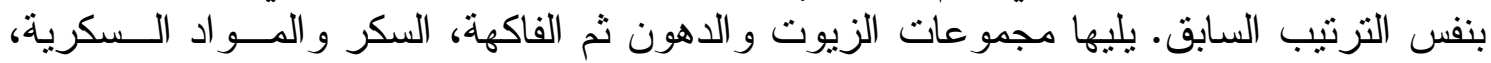

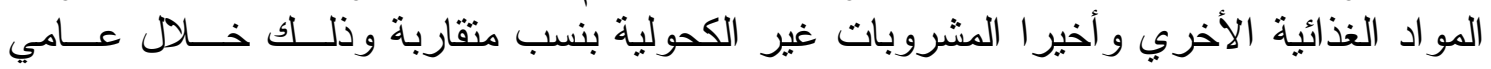
الدر اسة.

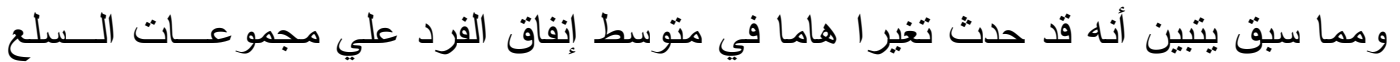

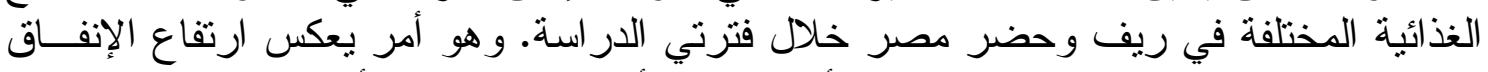

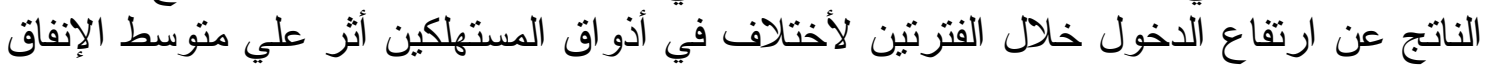
علي كل من المجمو عات النباتية و الحيو انية. ع - در داسة التباين بين متوسط الإنفاق الفردى علي المجموعات الغذائية المختلفة فــي ريف وحضر مصر:

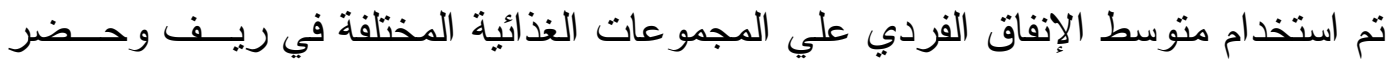

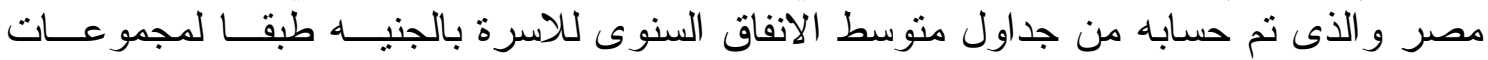

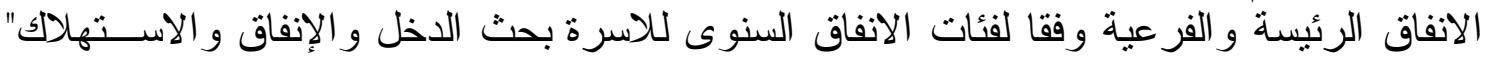




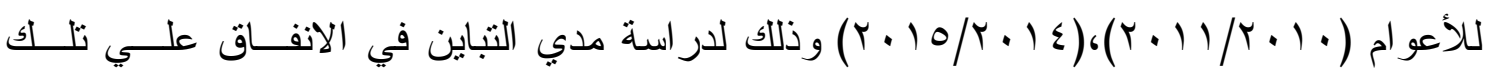

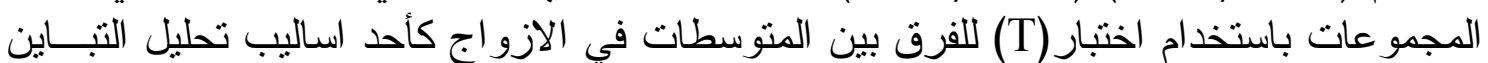

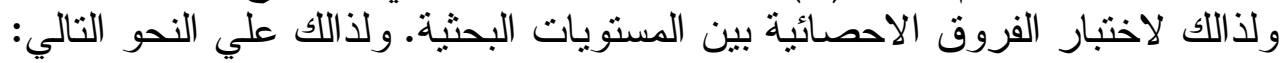

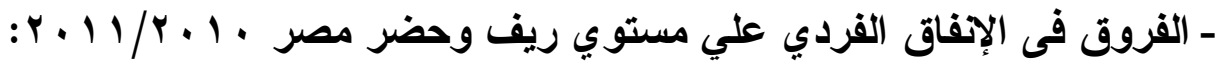

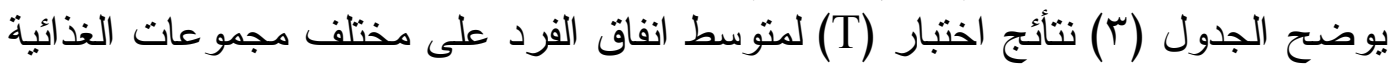

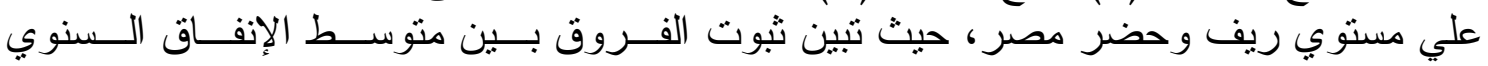

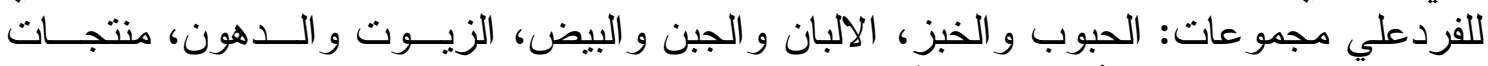

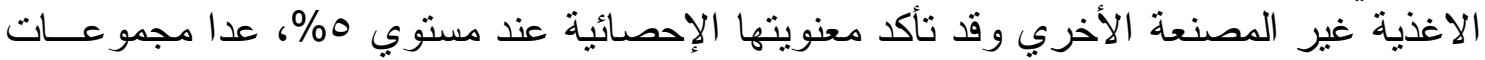

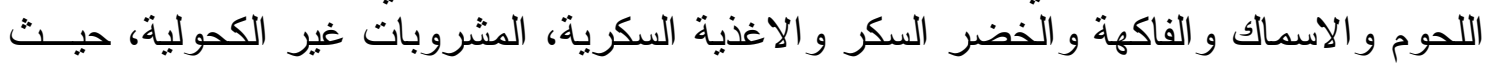
لم تتأكد معنويتها الإحصائية عند مستوي

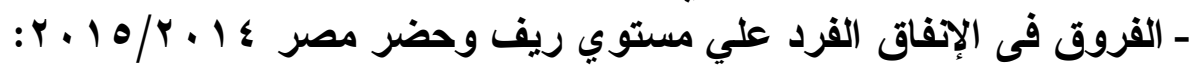

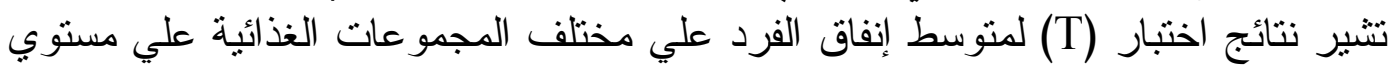

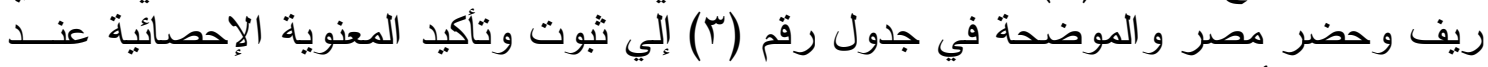

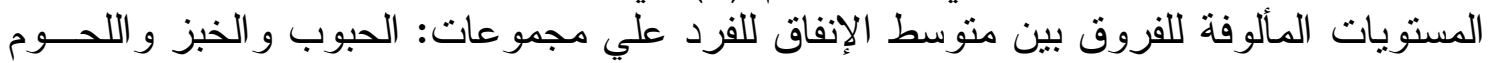
و الالبان و الجبن و البيض، الزيوت و الدهون و الخضر و السكر و الاغذية الإنية السكرية عدا مجمو عات

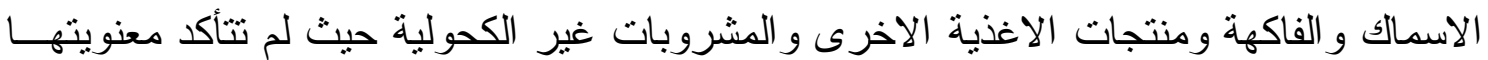

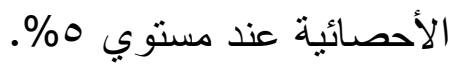

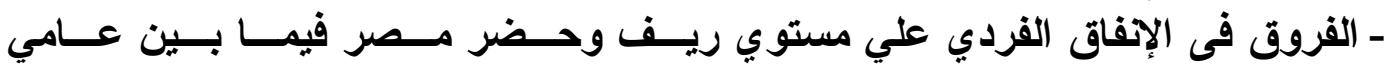

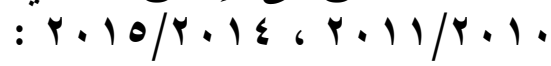

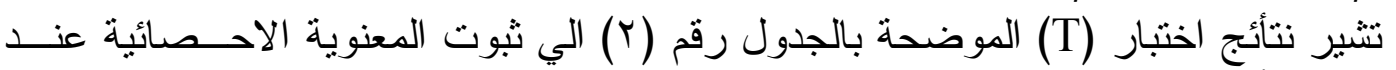

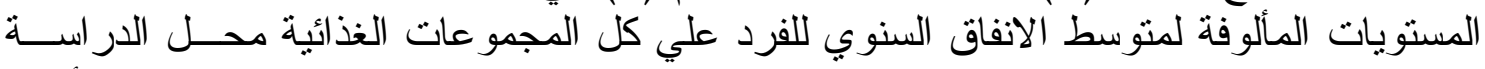

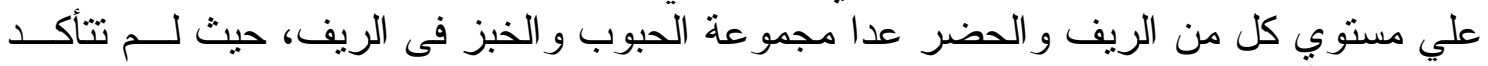

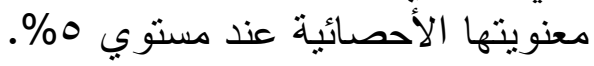

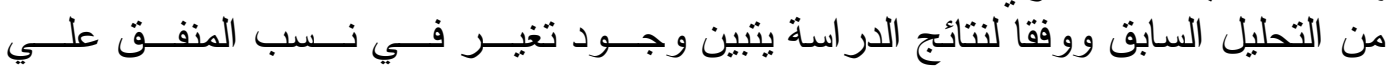

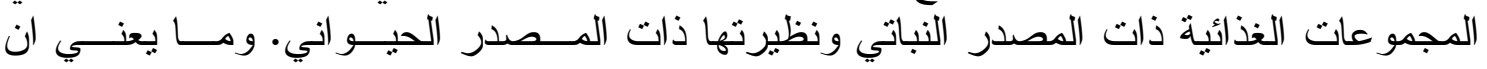

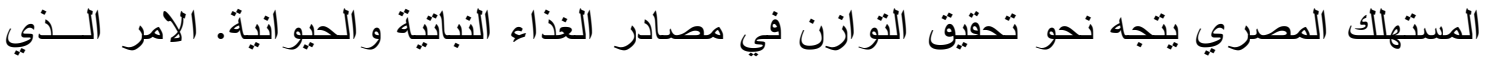

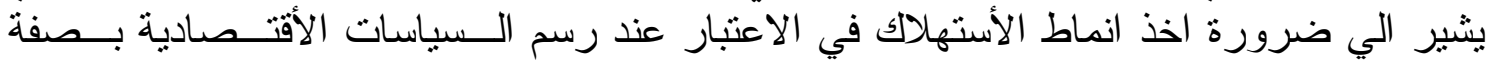

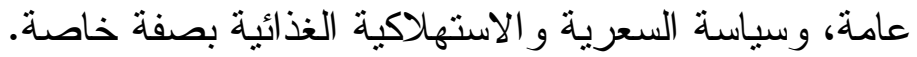

-در اسة الاختلاف في الاهمية النسبية للانفاق السنوي الفردي علية الغية مجموعات السلع الغذائية:

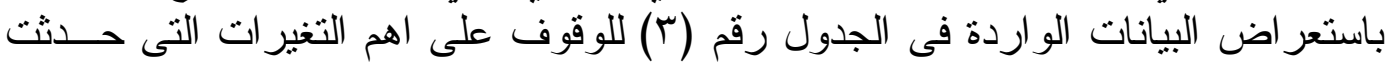

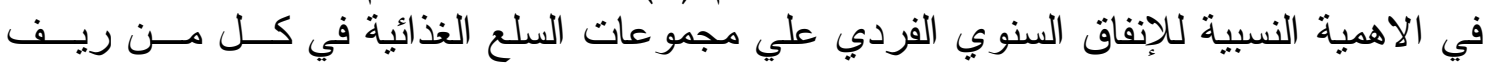

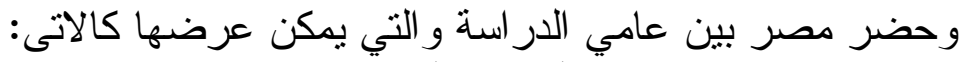
مجموعات ارتفعت الاهمية النسبية للإِفاق عليها فى الريف والئ والحضر:

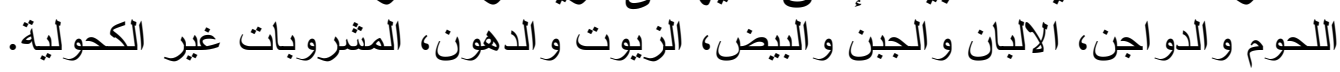

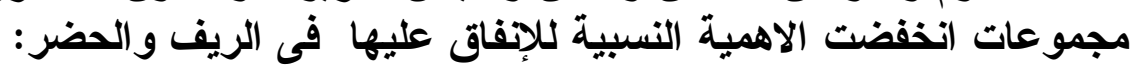

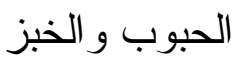
مجموعات ارتفعت اهميتها النسبية بين عامي الدراسة فى الريف وانخفضت فى الحضر

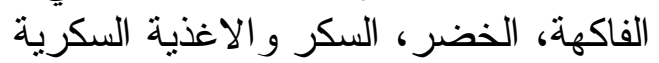
مجموعات لم تتغير اهميتها النسبية بين عامي الاراسة والثة وتشمل : الاسمالك و السكر 
من التحليل السابق اتضحً انه بزيادة الدخل الفردي فيما بين عامي الدراسة انخفضت نسبة الإنة

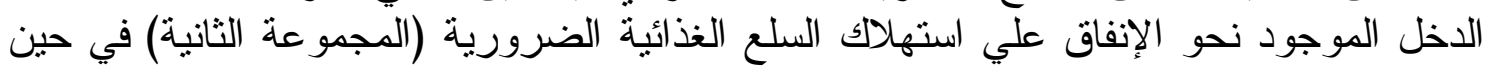

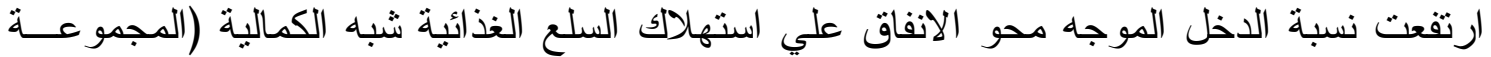

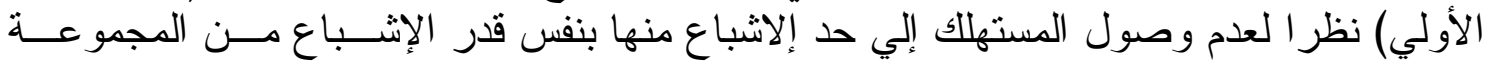

ثانياً: تقدير المرونات الإفاقية للمجموعات الغذائية في ريف وحضر مصر:

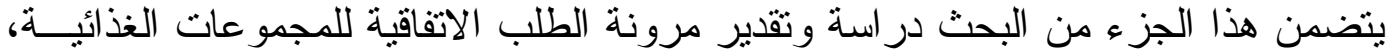

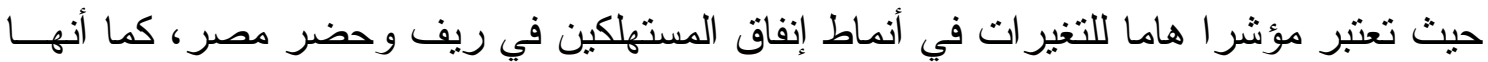

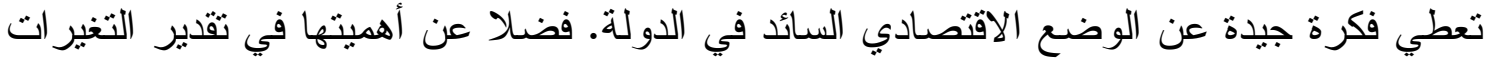

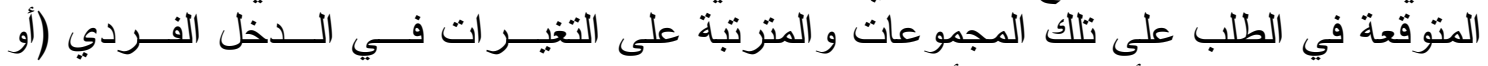

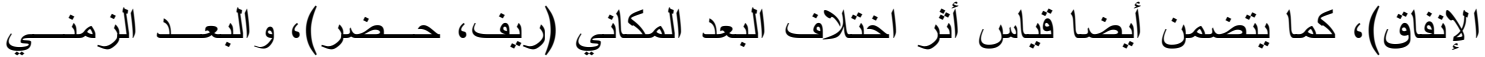

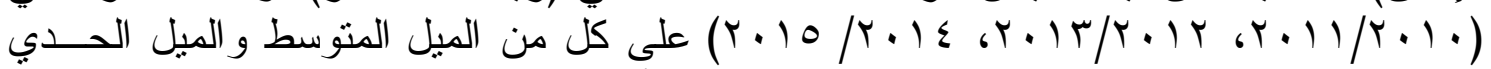

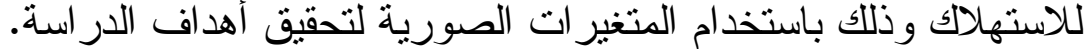

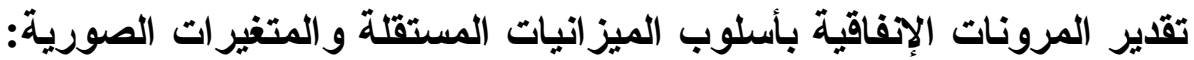

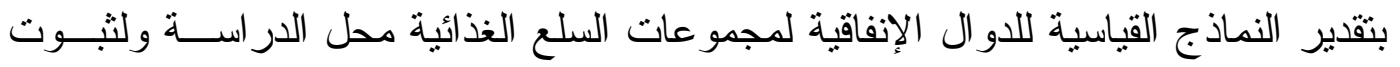

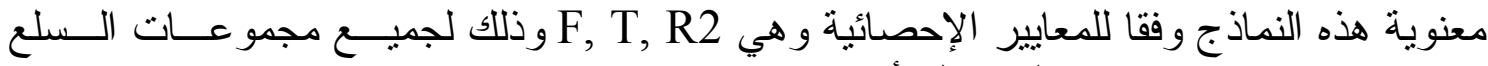

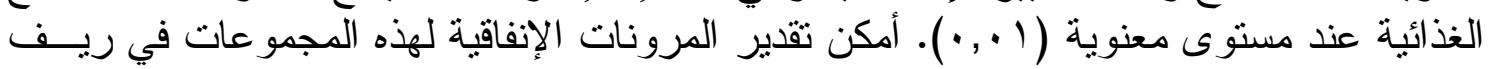

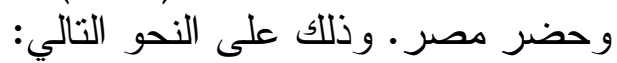

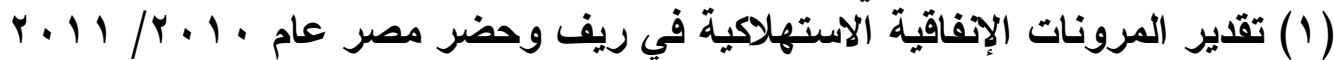

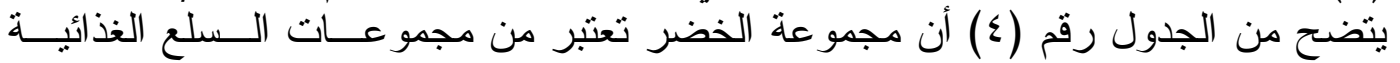

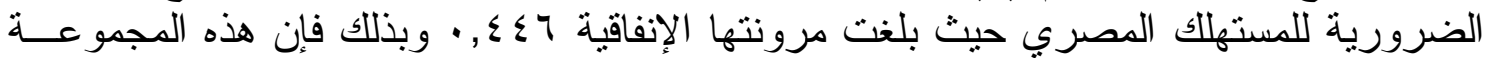

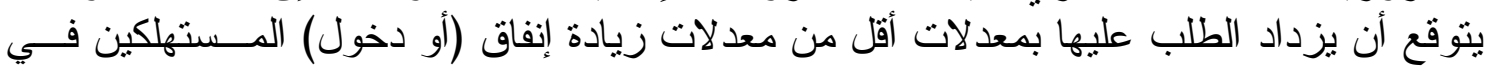
الريف و الحضر . 
Doi: 10.21608/ajas.2019.66200

http://ajas.journals.ekb.eg/

rer

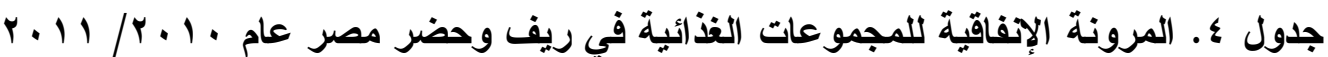

\begin{tabular}{|c|c|c|c|}
\hline \multicolumn{2}{|c|}{ المعنوية } & \multirow{2}{*}{ النموذج المقدر } & \multirow{2}{*}{ بند الاتفاق } \\
\hline الفرق & للنموذج & & \\
\hline- & $* *$ & 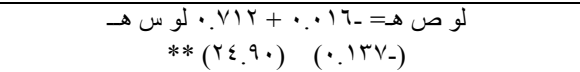 & \multirow{3}{*}{ الحبوب والخبز } \\
\hline$* *$ & $* *$ & 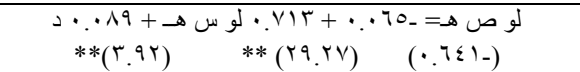 & \\
\hline$* *$ & $* *$ & 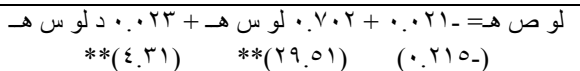 & \\
\hline- & $* *$ & 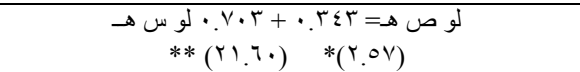 & \multirow{3}{*}{ 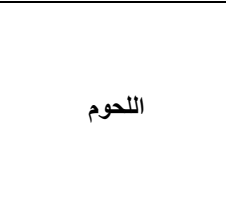 } \\
\hline- & $* *$ & 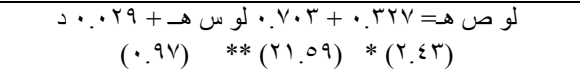 & \\
\hline- & $* *$ & 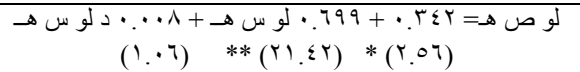 & \\
\hline- & $* *$ & 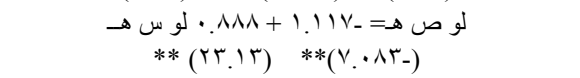 & \multirow{3}{*}{ الاسماك } \\
\hline$*$ & $* *$ & 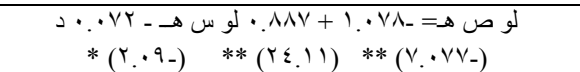 & \\
\hline- & $* *$ & 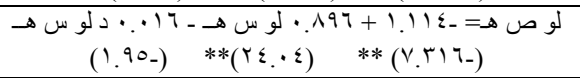 & \\
\hline- & $* *$ & 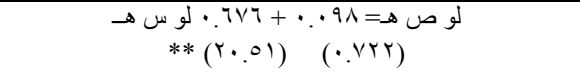 & \multirow{3}{*}{ الالبان و الجبن } \\
\hline$* *$ & $* *$ & 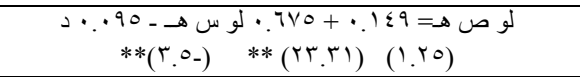 & \\
\hline$* *$ & $* *$ & $\begin{array}{c}\text { لو ص هـ } \\
\text { ه }\end{array}$ & \\
\hline- & $* *$ & 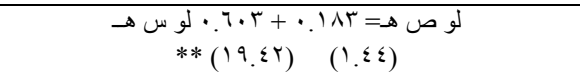 & \multirow{3}{*}{ الزيوت والدهون } \\
\hline$* *$ & $* *$ & 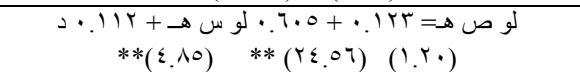 & \\
\hline$* *$ & $* *$ & $\begin{array}{c}\text { لو ص هـ } \\
\text { ه }\end{array}$ & \\
\hline- & $* *$ & 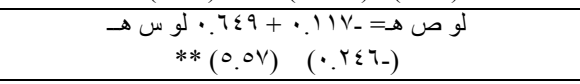 & \multirow{3}{*}{ الفاكهة } \\
\hline - & $* *$ & 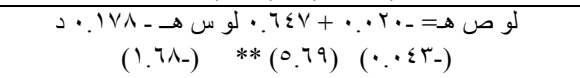 & \\
\hline- & $* *$ & 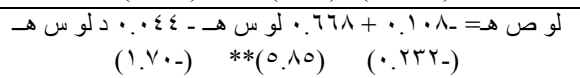 & \\
\hline- & $* *$ & 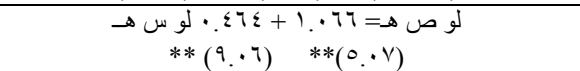 & \multirow{3}{*}{ الخضر } \\
\hline- & $* *$ & 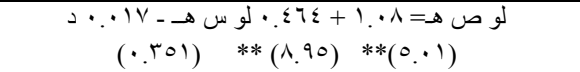 & \\
\hline- & $* *$ & 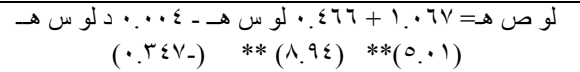 & \\
\hline - & $* *$ & 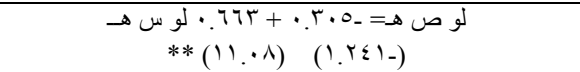 & \multirow{3}{*}{ السكر و الأغذية السكرية } \\
\hline- & $* *$ & 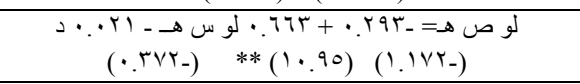 & \\
\hline- & $* *$ & 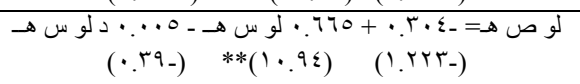 & \\
\hline- & $* *$ & 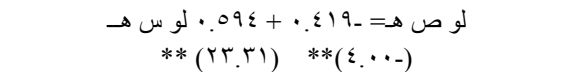 & \multirow{3}{*}{ مصنجات تحت أي بند غير } \\
\hline$*$ & $* *$ & 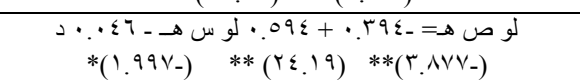 & \\
\hline$*$ & $* *$ & 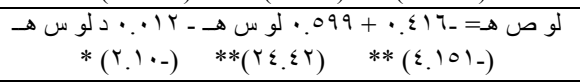 & \\
\hline- & $* *$ & 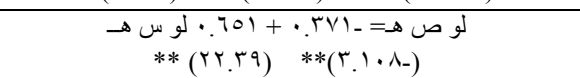 & \multirow{3}{*}{ المشروبات الغير } \\
\hline- & $* *$ & 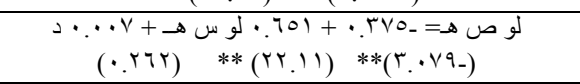 & \\
\hline- & $* *$ & 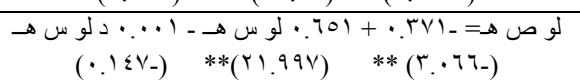 & \\
\hline
\end{tabular}

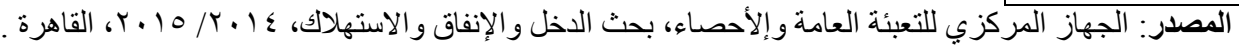




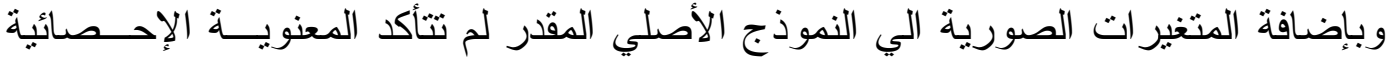

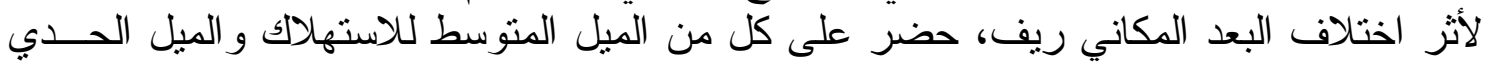

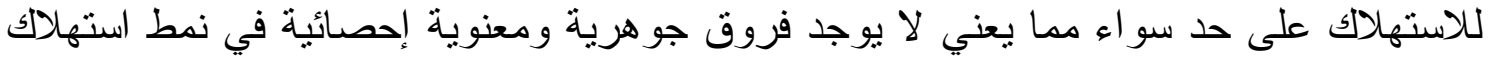

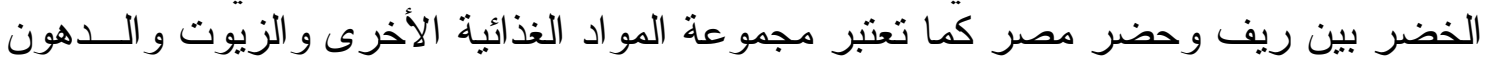

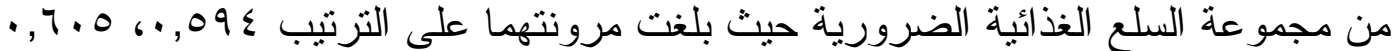

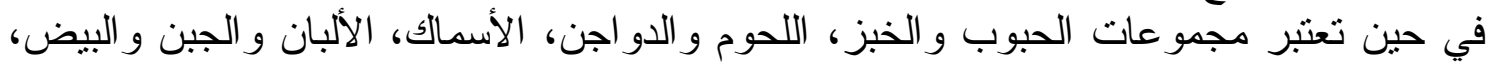

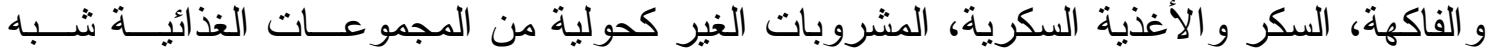

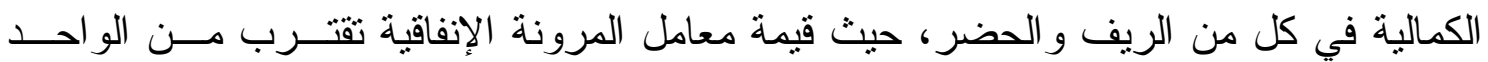

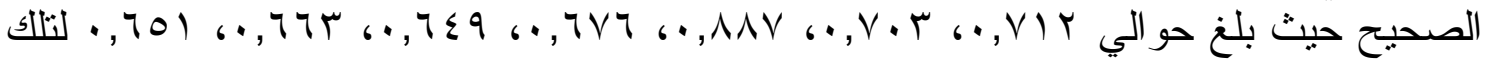

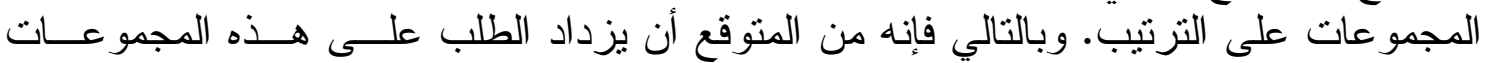

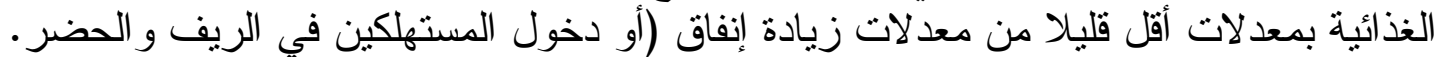

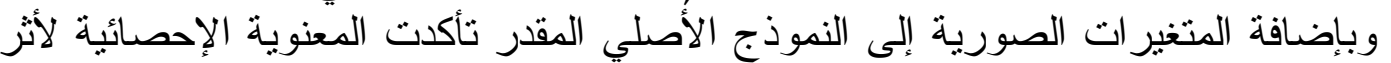

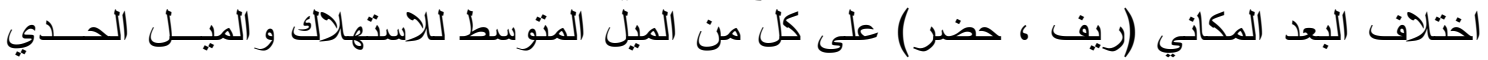

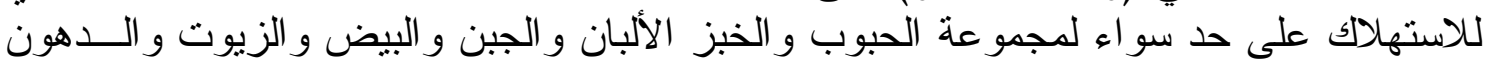

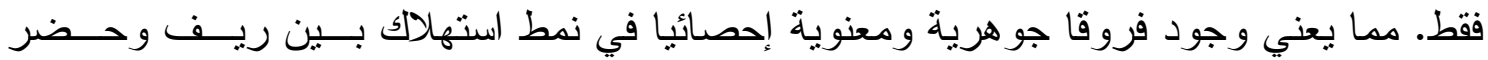

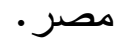

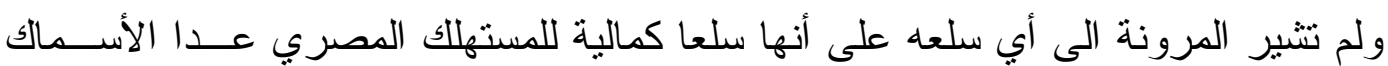

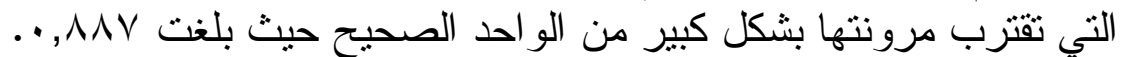

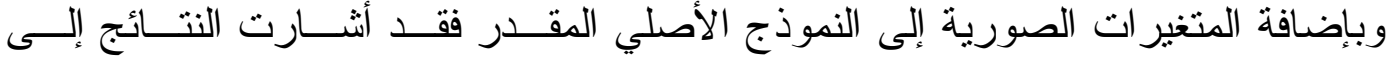

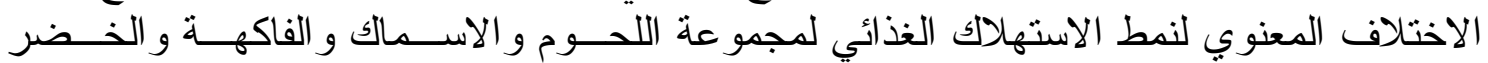

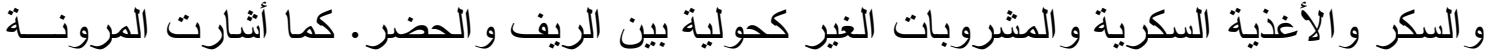

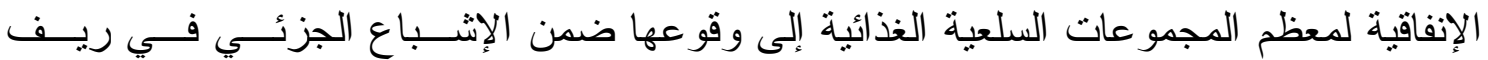

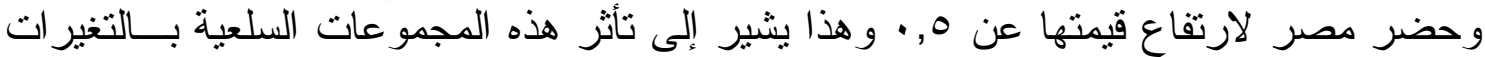

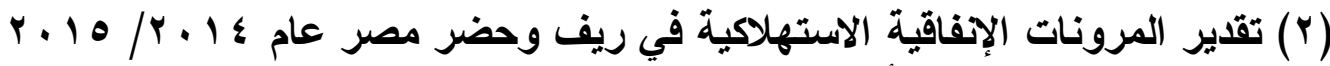

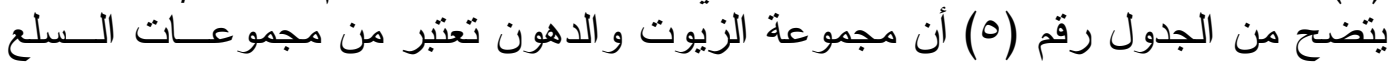

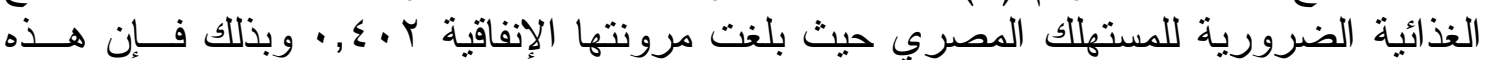

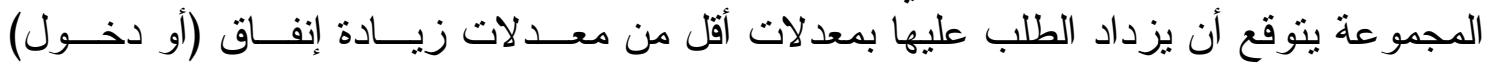

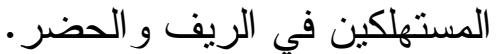




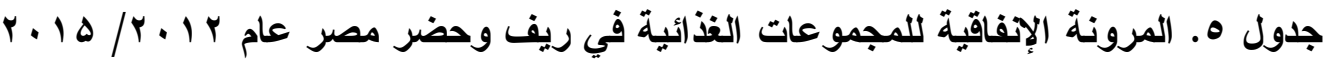

\begin{tabular}{|c|c|c|c|}
\hline \multicolumn{2}{|c|}{ المعنوية } & \multirow{2}{*}{ النموذج المقدر } & \multirow{2}{*}{ بند الانفاق } \\
\hline الفرق & ل للنموذج & & \\
\hline - & $* *$ & 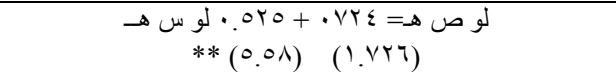 & \multirow{3}{*}{ الحبوب والخبز } \\
\hline * & $* *$ & 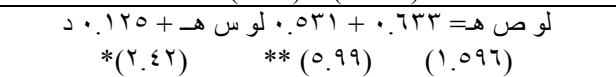 & \\
\hline$*$ & $* *$ & 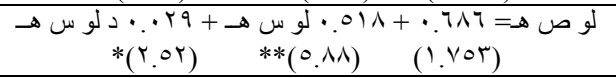 & \\
\hline- & $* *$ & 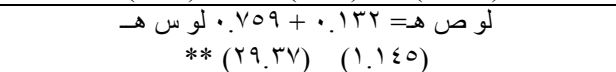 & \multirow{3}{*}{ 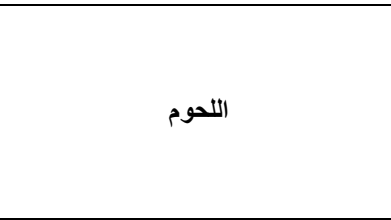 } \\
\hline$* *$ & $* *$ & 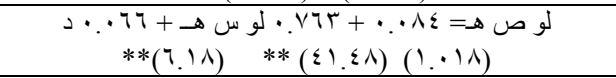 & \\
\hline$* *$ & $* *$ & 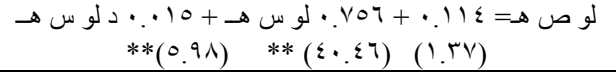 & \\
\hline- & $* *$ & 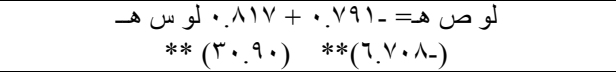 & \multirow{3}{*}{ 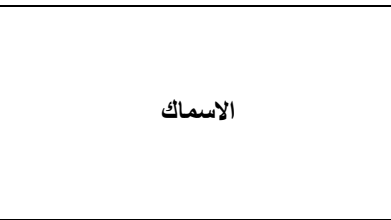 } \\
\hline- & $* *$ & 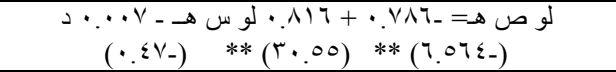 & \\
\hline- & $* *$ & 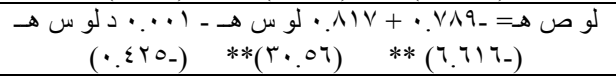 & \\
\hline- & $* *$ & 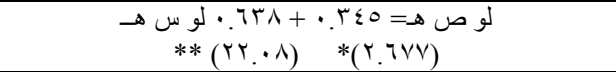 & \multirow{3}{*}{ الالبان والجبن } \\
\hline$* *$ & $* *$ & 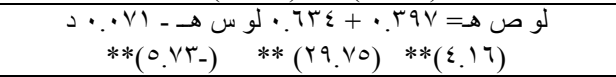 & \\
\hline$* *$ & $* *$ & 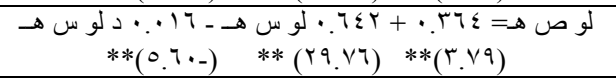 & \\
\hline- & $* *$ & 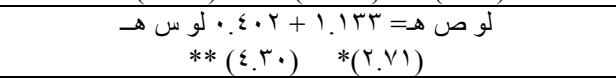 & \multirow{3}{*}{ الزيوت و الدهون } \\
\hline$* *$ & $* *$ & 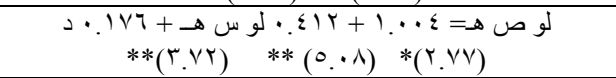 & \\
\hline$* *$ & $* *$ & 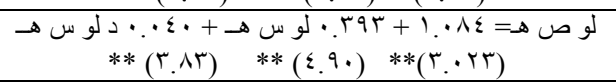 & \\
\hline- & $* *$ & 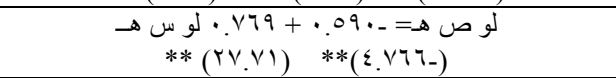 & \multirow{3}{*}{ الفاكهة } \\
\hline$* *$ & $* *$ & 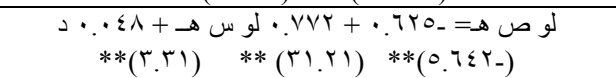 & \\
\hline$* *$ & $* *$ & 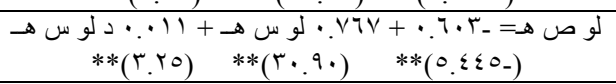 & \\
\hline - & $* *$ & 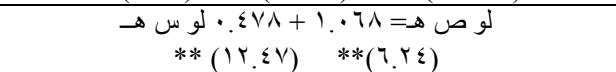 & \multirow{3}{*}{ الخضر } \\
\hline$* *$ & $* *$ & 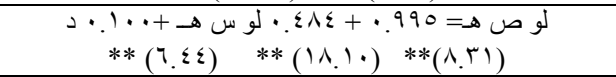 & \\
\hline$* *$ & $* *$ & 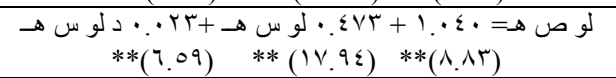 & \\
\hline - & $* *$ & 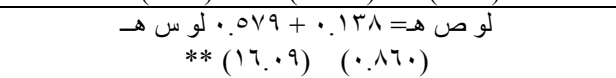 & \multirow{3}{*}{ السكر والأغذية السكرية } \\
\hline$* *$ & $* *$ & 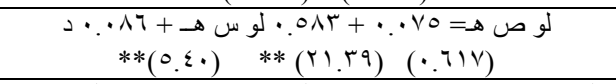 & \\
\hline$* *$ & $* *$ & 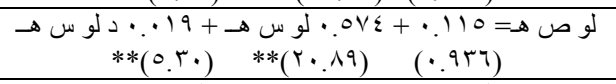 & \\
\hline- & $* *$ & 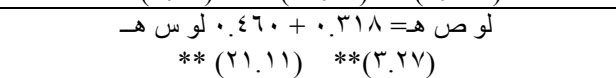 & \multirow{3}{*}{ منتجات غذائية غير مصنعه تحت أي بند } \\
\hline$* *$ & $* *$ & 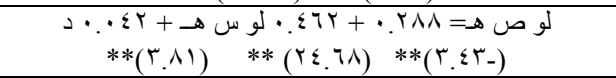 & \\
\hline$* *$ & $* *$ & 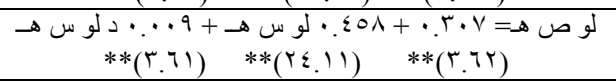 & \\
\hline- & $* *$ & 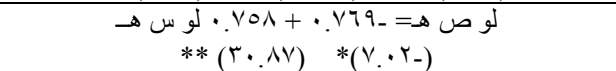 & \multirow{3}{*}{ المشروبات الغير كحولية } \\
\hline- & $* *$ & 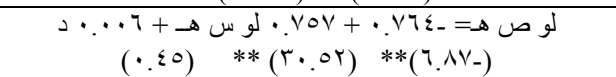 & \\
\hline - & $* *$ & 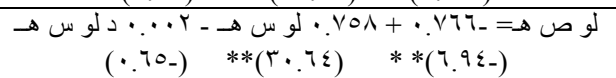 & \\
\hline
\end{tabular}

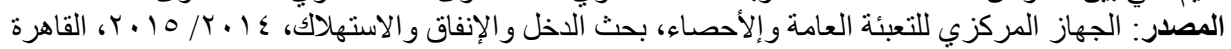


وبإضافة المتغيرات الصورية الي النموذج الأصلي المقدر تأكدت المعنوية الإحصائية لأثر

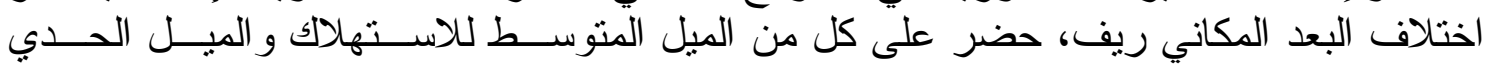

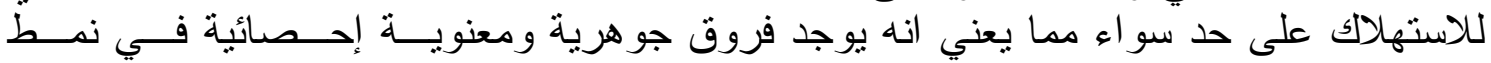

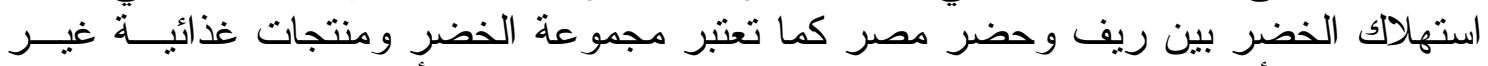

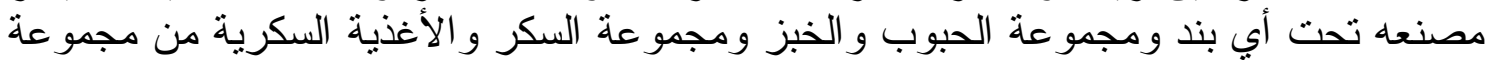

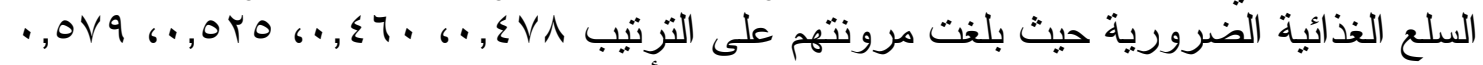

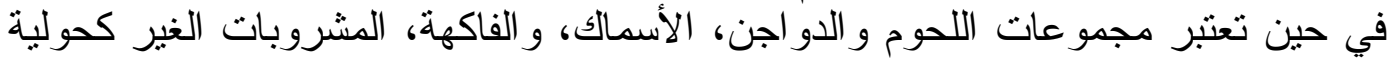

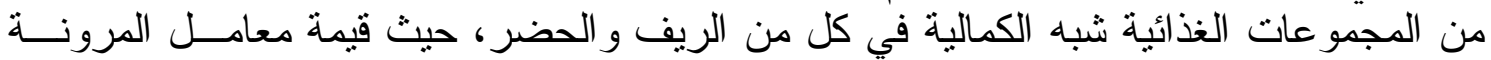

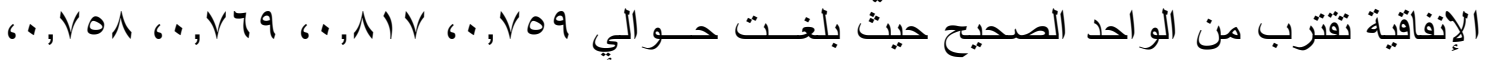

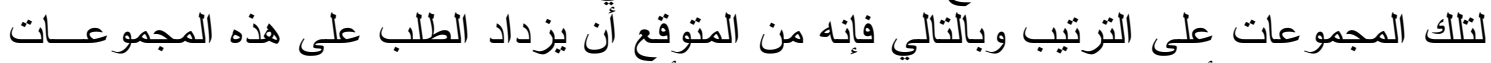

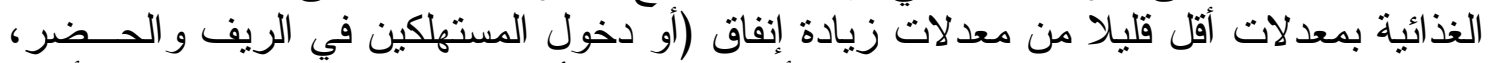

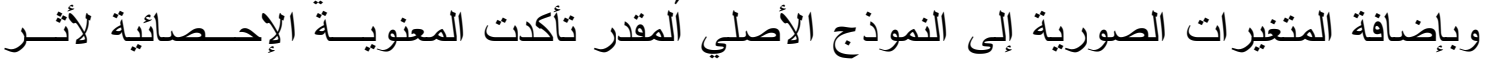

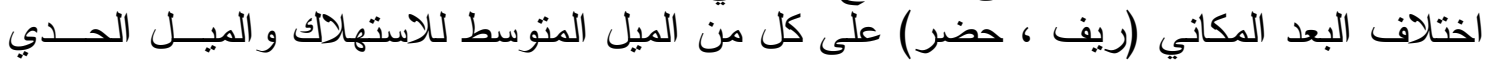

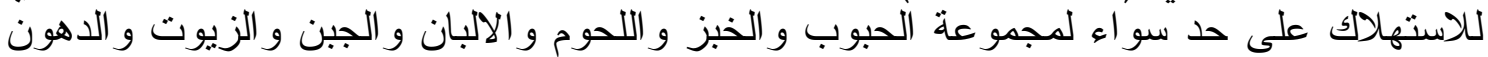

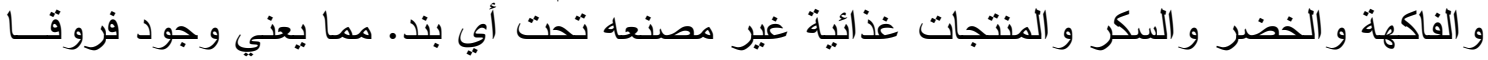

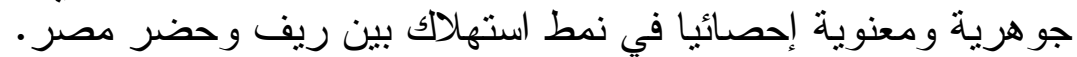

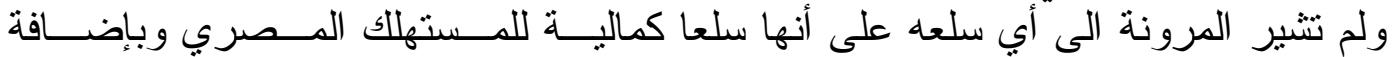

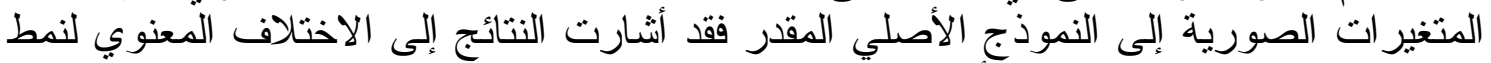

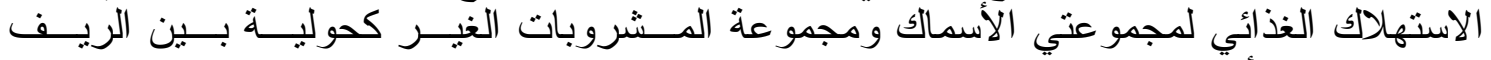

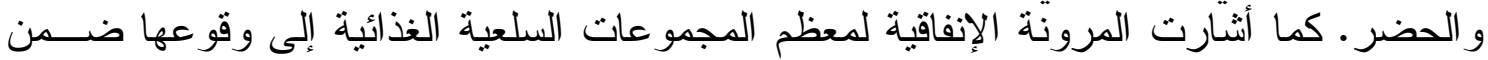

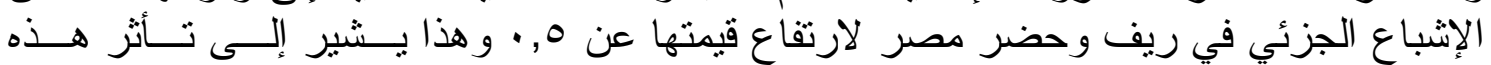
المجموعات السلعيةً بالتغير ات الداخلية.

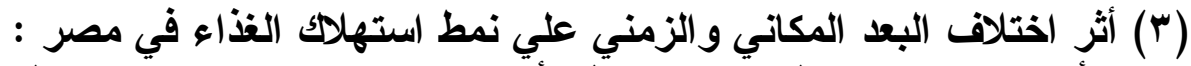

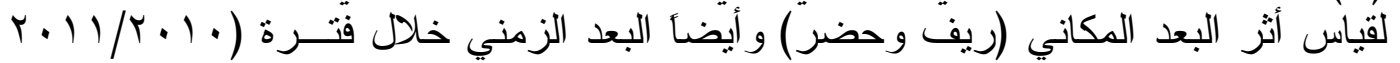

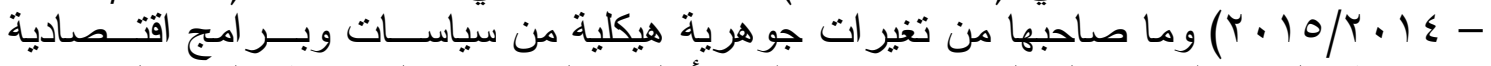

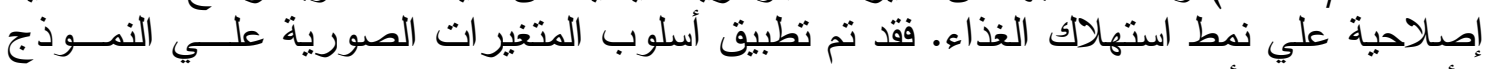

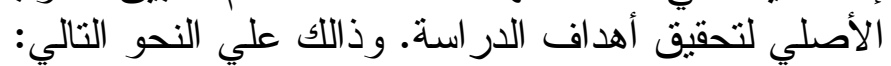

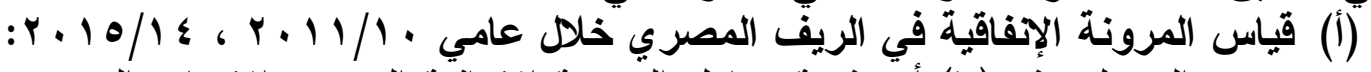

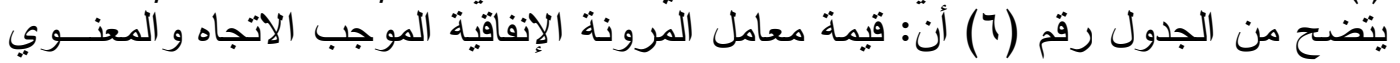

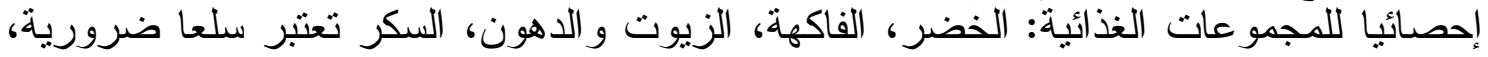
حيث بلغت

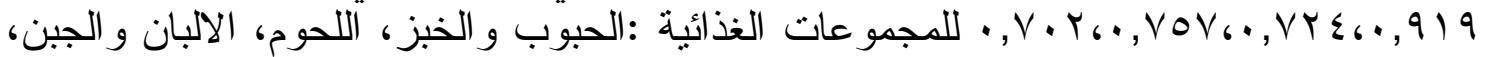

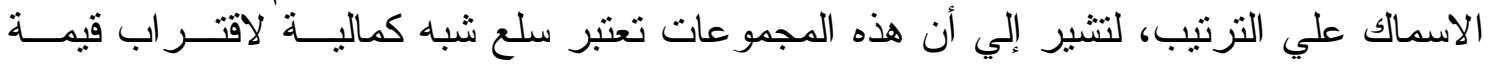

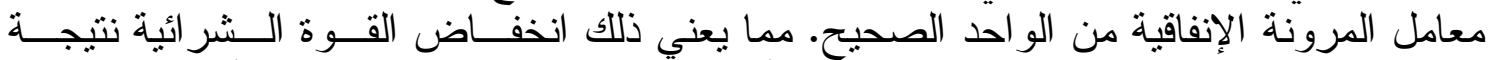

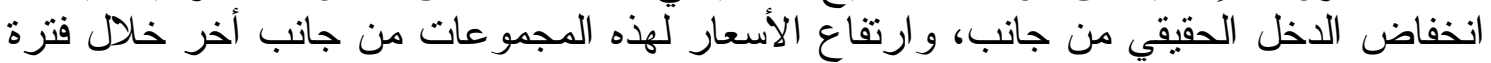

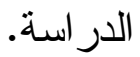

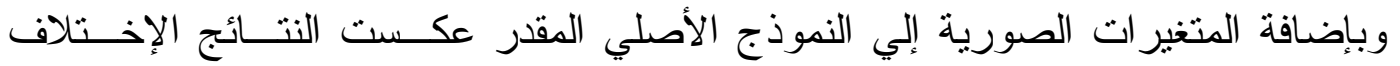

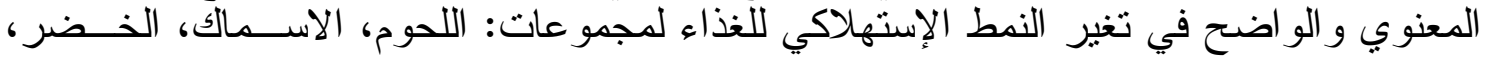

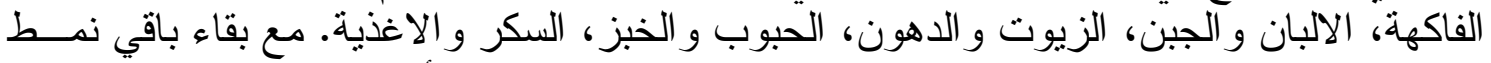

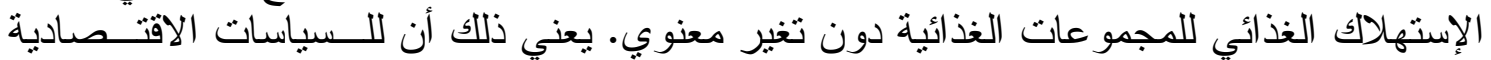

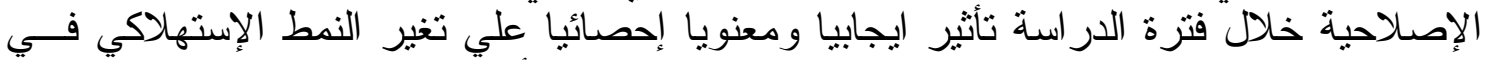

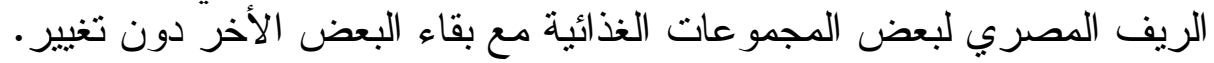


Doi: 10.21608/ajas.2019.66200

http://ajas.journals.ekb.eg/

rer

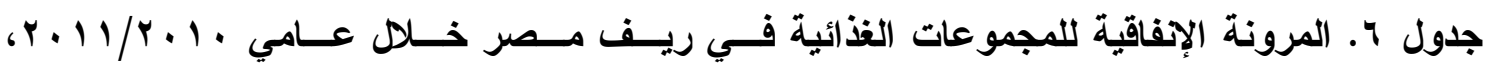

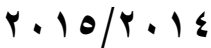

\begin{tabular}{|c|c|c|c|}
\hline \multicolumn{2}{|c|}{ المعنوية: } & \multirow{2}{*}{ النموذج المقدر } & \multirow{2}{*}{ بند الانفاق } \\
\hline الفرق & لللنموذج & & \\
\hline- & $* *$ & 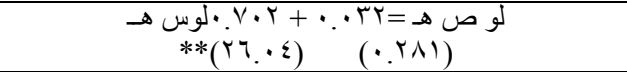 & \multirow{3}{*}{ الحبوب والنشويات } \\
\hline$* *$ & $* *$ & 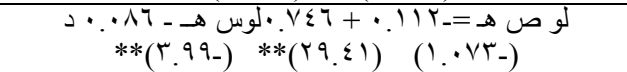 & \\
\hline$* *$ & $* *$ & 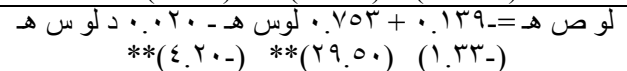 & \\
\hline- & $* *$ & 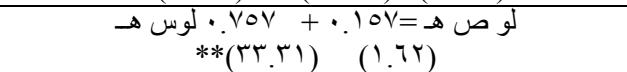 & \multirow{3}{*}{ 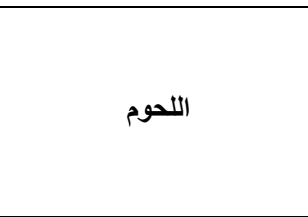 } \\
\hline$*$ & $* *$ & 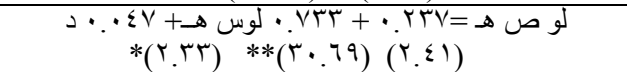 & \\
\hline$*$ & $* *$ & 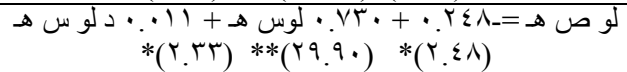 & \\
\hline- & $* *$ & 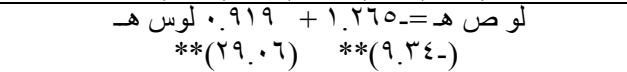 & \multirow{3}{*}{ الاسماك } \\
\hline- & $* *$ & 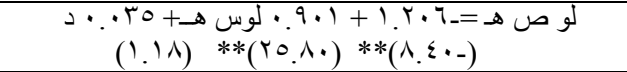 & \\
\hline- & $* *$ & 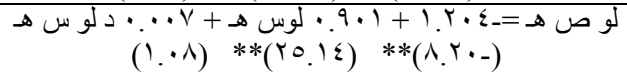 & \\
\hline- & $* *$ & 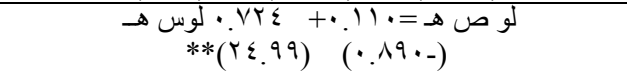 & \multirow{3}{*}{ الالبان والجبن } \\
\hline ** & $* *$ & 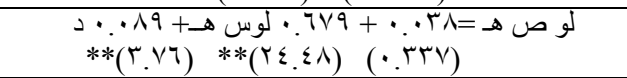 & \\
\hline$* *$ & $* *$ & 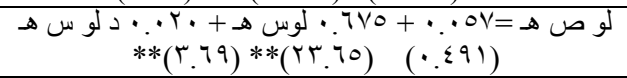 & \\
\hline- & $* *$ & 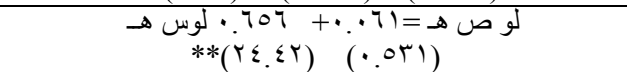 & \multirow{3}{*}{ الزيوت والدهون } \\
\hline$* *$ & $* *$ & 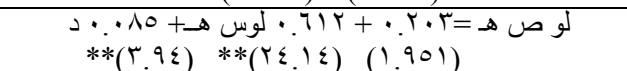 & \\
\hline$* *$ & $* *$ & 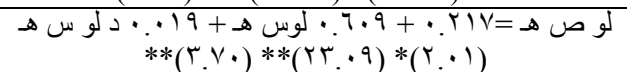 & \\
\hline- & $* *$ & 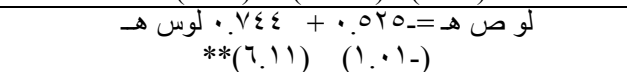 & \multirow{3}{*}{ الفاكهة } \\
\hline- & $* *$ & 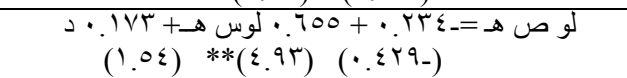 & \\
\hline - & $* *$ & 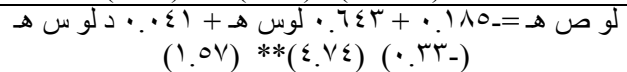 & \\
\hline- & $* *$ & 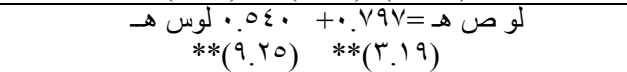 & \multirow{3}{*}{ الخضر } \\
\hline$*$ & $* *$ & 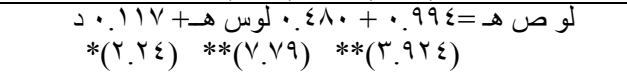 & \\
\hline$*$ & $* *$ & 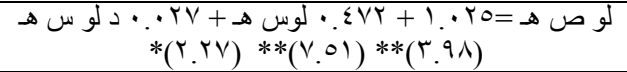 & \\
\hline - & $* *$ & 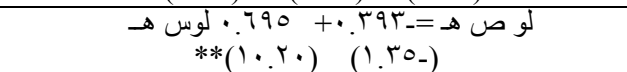 & \multirow{3}{*}{ السكر والاغذية } \\
\hline$*$ & $* *$ & 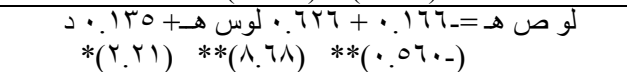 & \\
\hline$*$ & $* *$ & 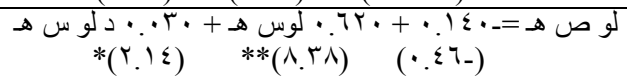 & \\
\hline - & $* *$ & 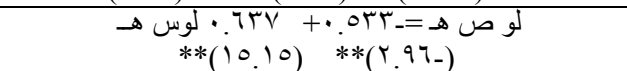 & \multirow{3}{*}{ منتجات الأغذية الغير مصنعه } \\
\hline$* *$ & $* *$ & 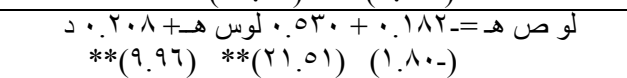 & \\
\hline$* *$ & $* *$ & 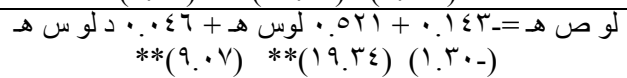 & \\
\hline- & $* *$ & 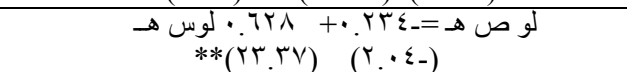 & \multirow{3}{*}{ المشروبات غبر الكحول } \\
\hline$* *$ & $* *$ & 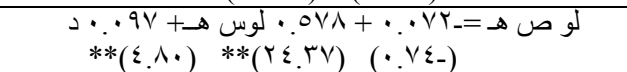 & \\
\hline$* *$ & $* *$ & 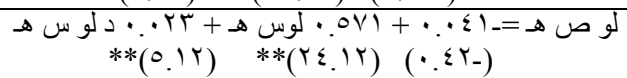 & \\
\hline
\end{tabular}




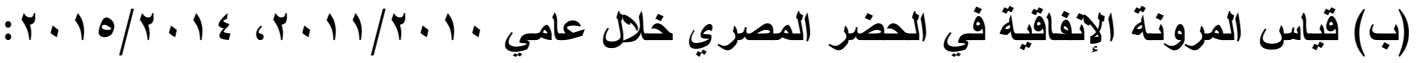

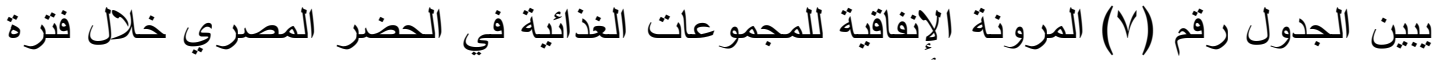

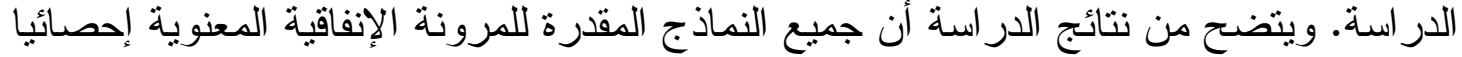

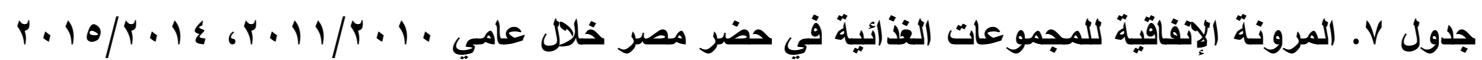

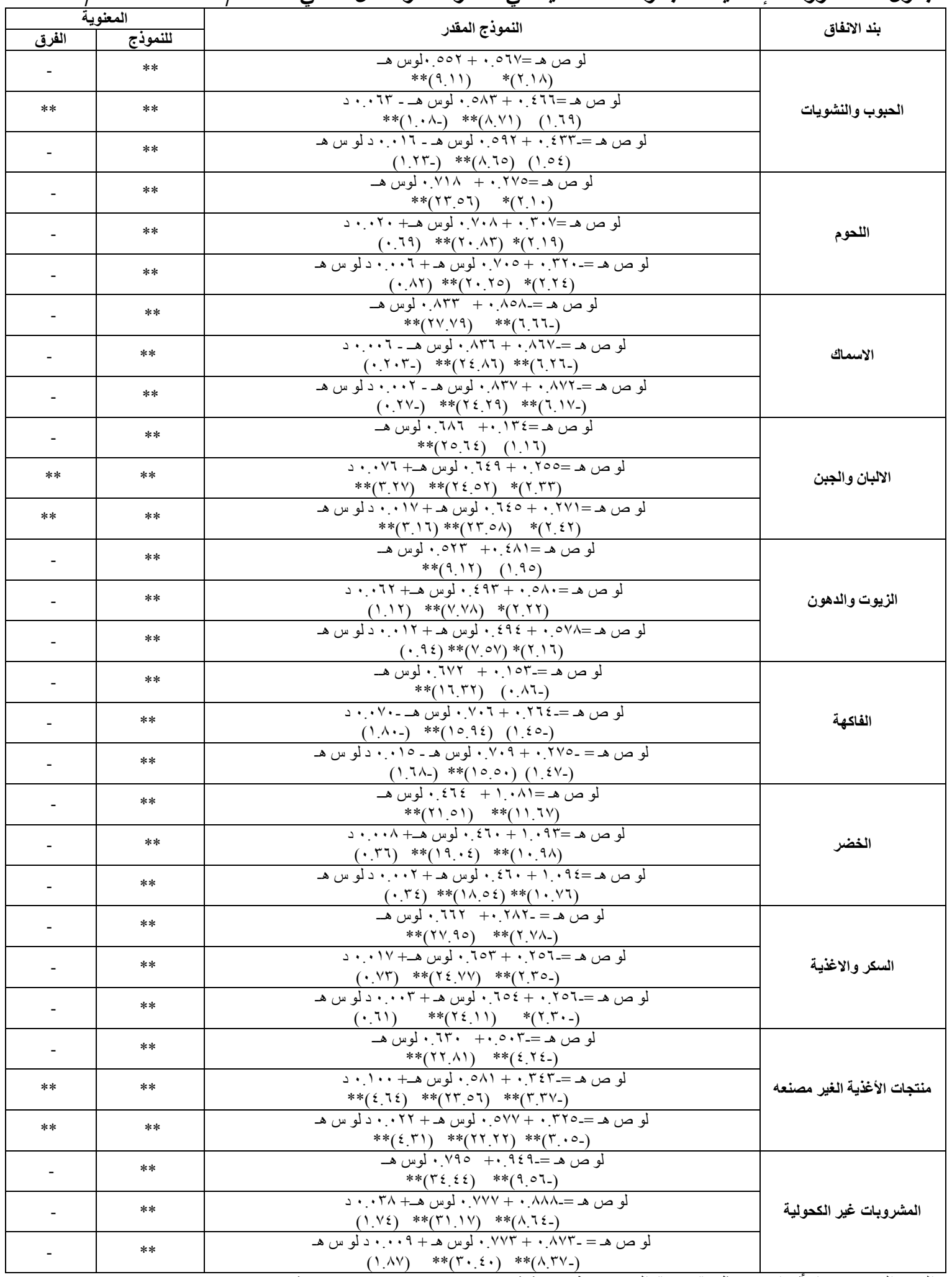

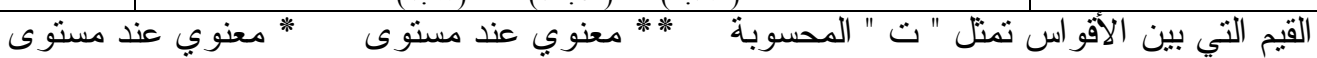

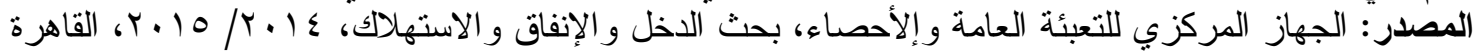




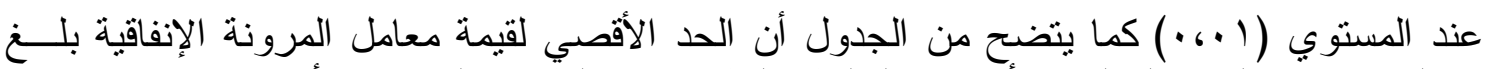

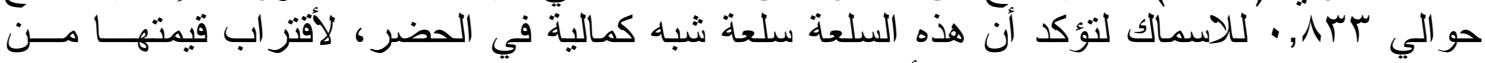

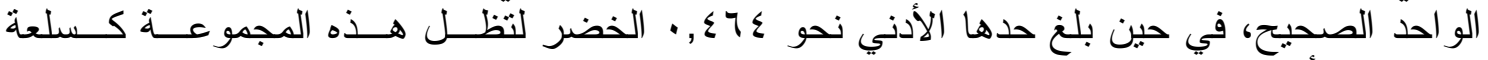

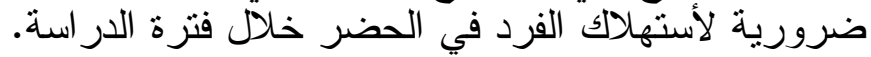

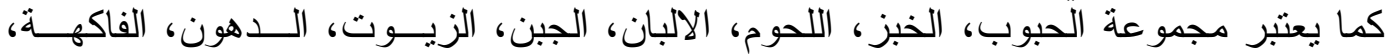

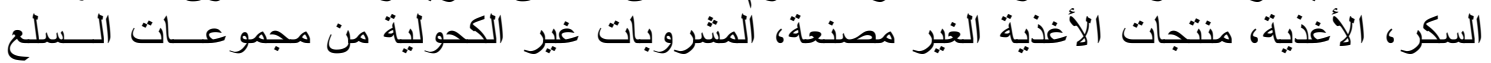

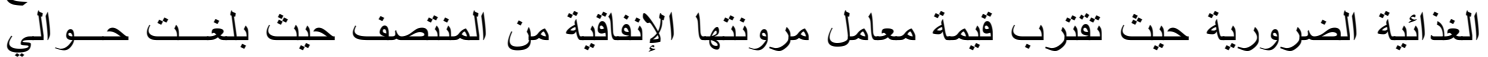
و وبل

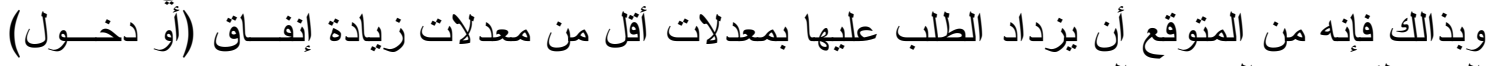

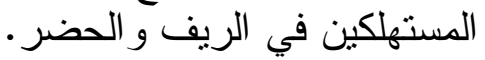

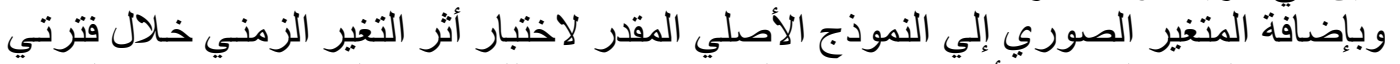

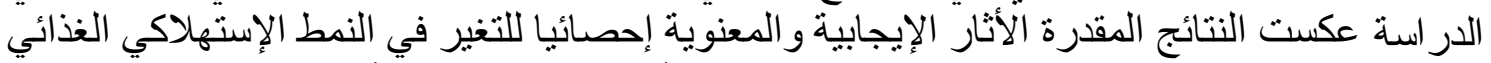

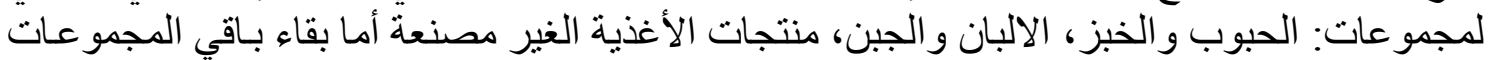

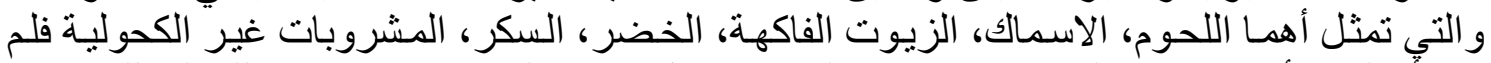

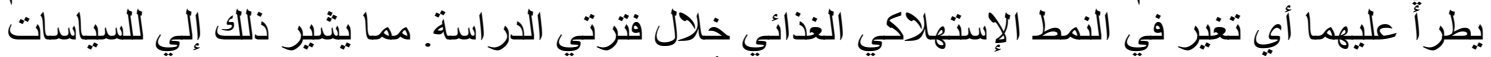

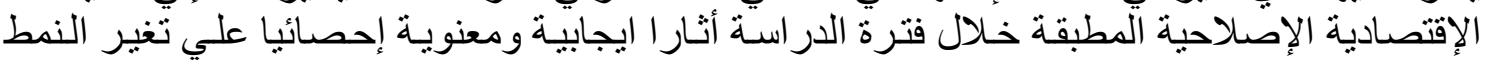

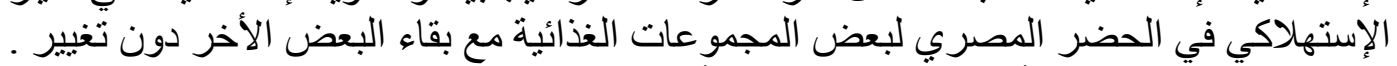

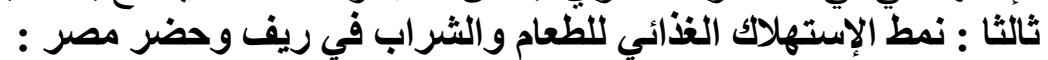

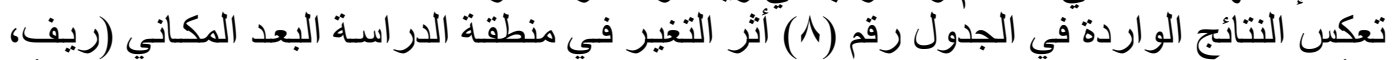

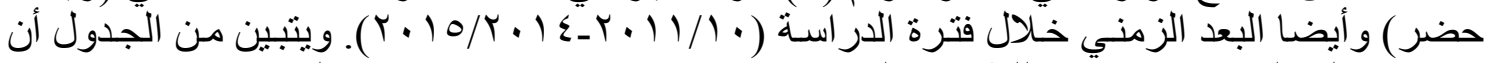

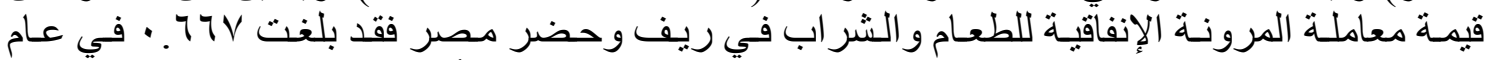

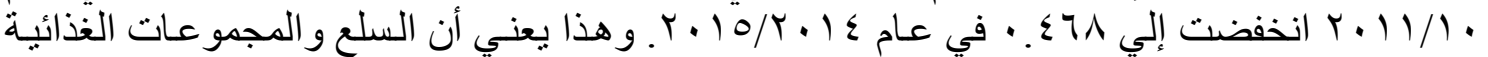

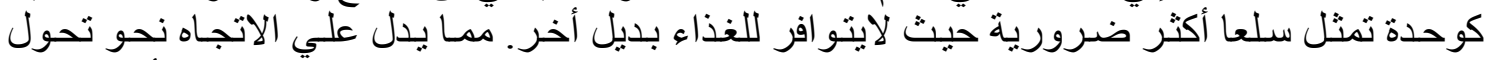

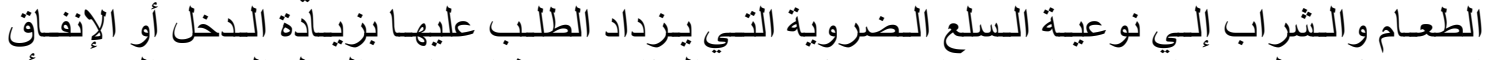

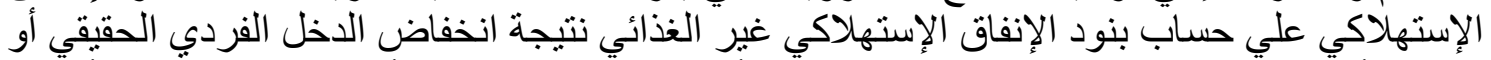

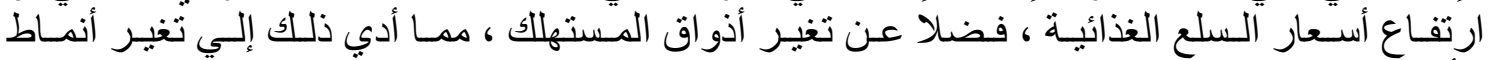
الأستهلاك الغذائي

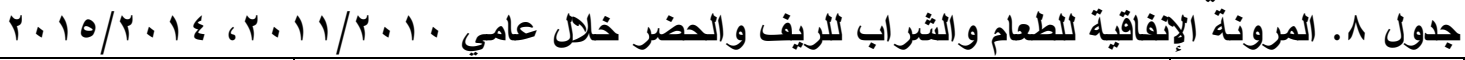

\begin{tabular}{|c|c|c|c|}
\hline \multicolumn{2}{|c|}{ المعنويةة } & \multirow{2}{*}{ النموذج المقدر } & \multirow{2}{*}{ بند الاففاق } \\
\hline الفرق & للنموذج & & \\
\hline - & $* *$ & 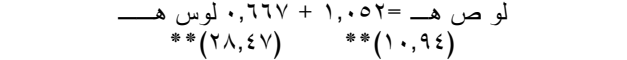 & \multirow{3}{*}{ 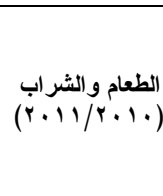 } \\
\hline - & $* *$ & 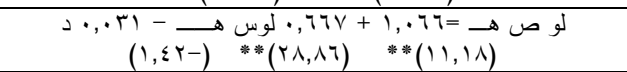 & \\
\hline$* *$ & $* *$ & 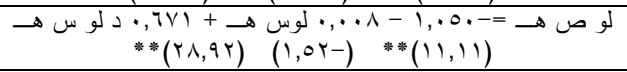 & \\
\hline - & $* *$ & 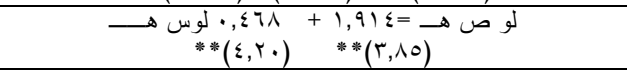 & \multirow{3}{*}{ 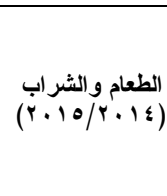 } \\
\hline - & $* *$ & 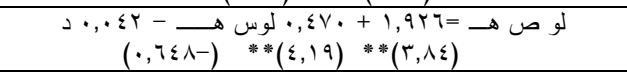 & \\
\hline - & $* *$ & 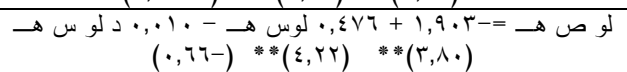 & \\
\hline - & $* *$ & 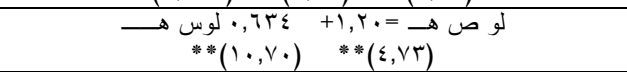 & \multirow{3}{*}{ الطعام و الثر اب (ريف) } \\
\hline - & $* *$ & 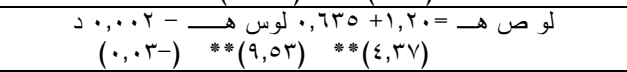 & \\
\hline - & $* *$ & 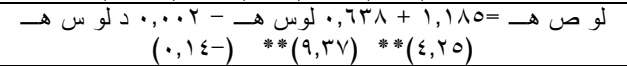 & \\
\hline - & $* *$ & 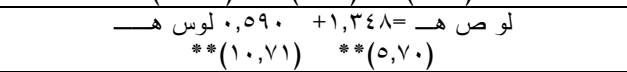 & \multirow{3}{*}{ الطعام و الثر اب) } \\
\hline - & $* *$ & 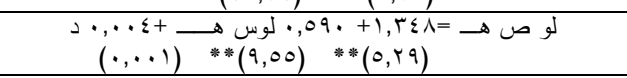 & \\
\hline- & $* *$ & 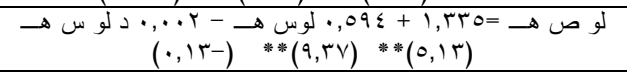 & \\
\hline
\end{tabular}

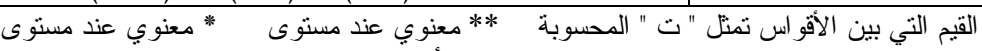

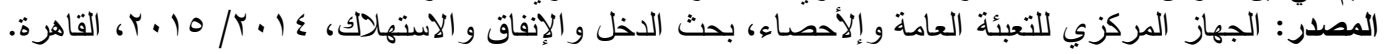




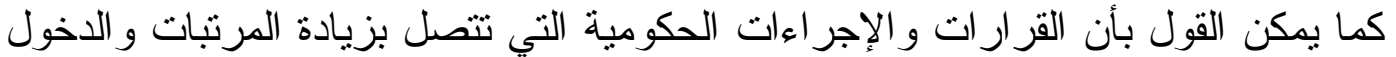

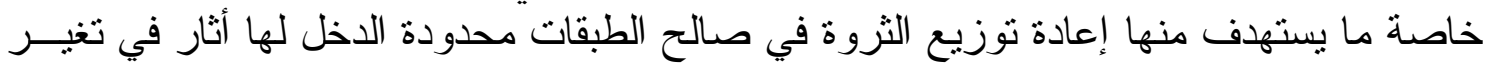

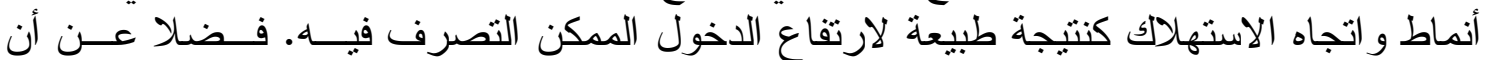

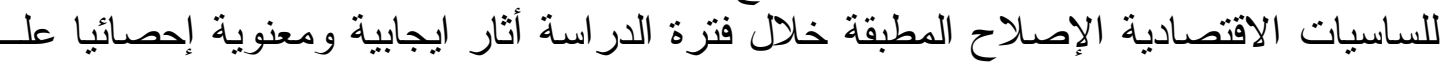

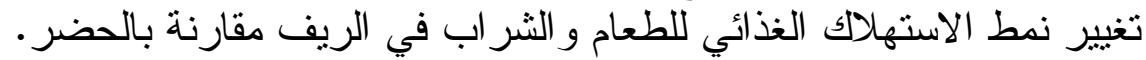

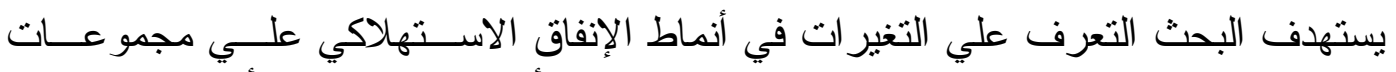

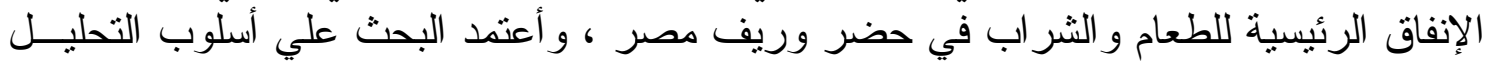

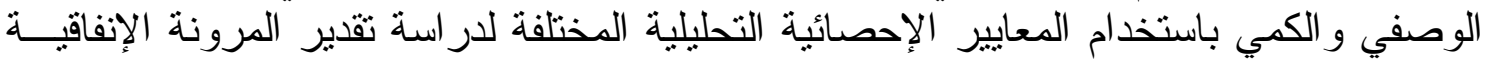

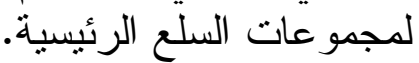

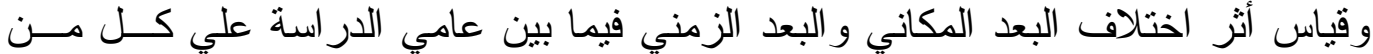

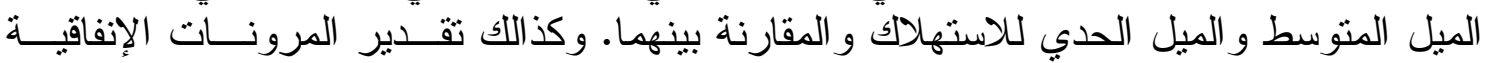
لمجمو عات السلع الغذائية المختلفة.

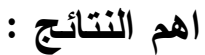

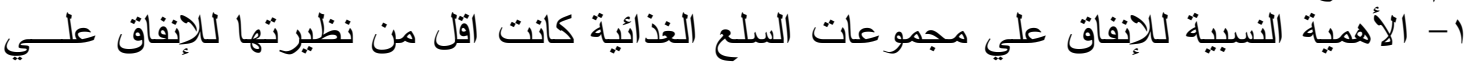

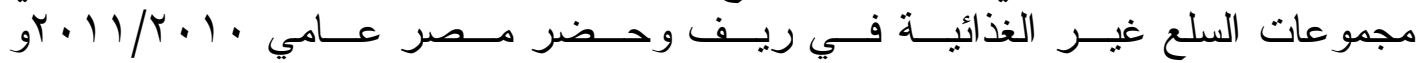

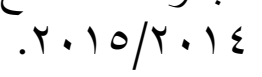
r- يزداد الانفاق الفردى و الأسرى علي الطعام و الثر اب الفئه الانفاقية.

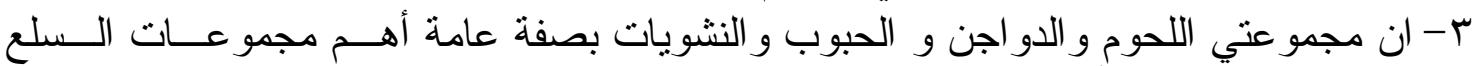

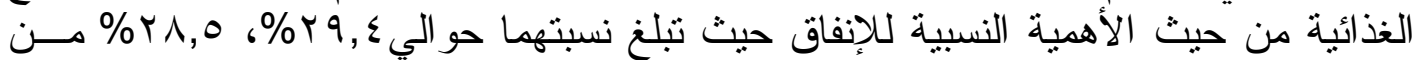

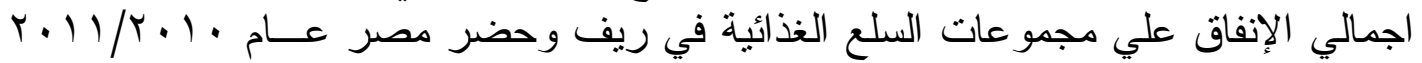

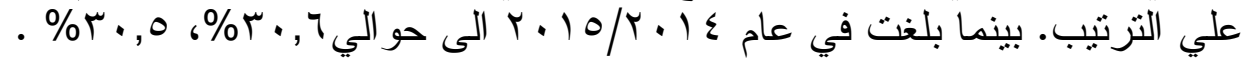

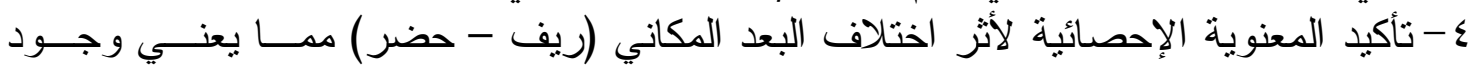

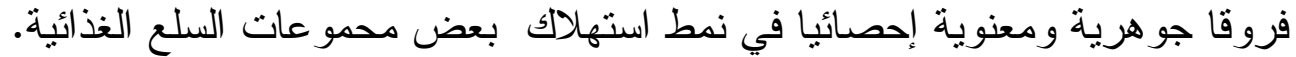

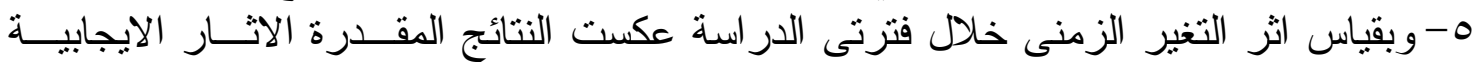

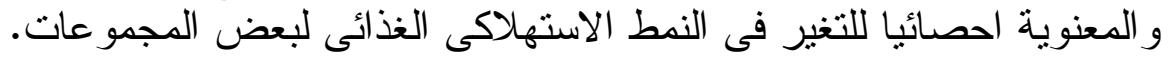

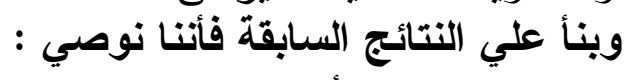

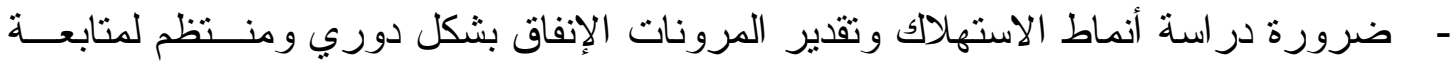

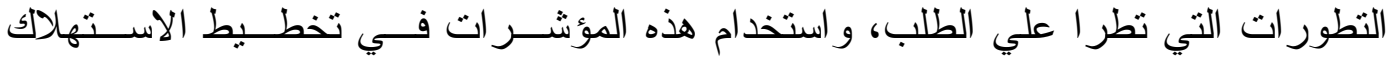

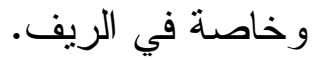

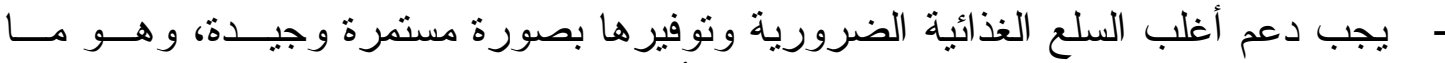
يعكس معامل المرونة حيث تعتبر منخفضة لأغلب المجموعات الغورة الغذائية وبالتــالي تعتبـــر

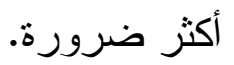

أنشرف محمد علي (دكتور)، أنشرف السيد مصطفي(دكتور) ، دراسة تحليلية لأنماط الاستهلاكي الغـــائي

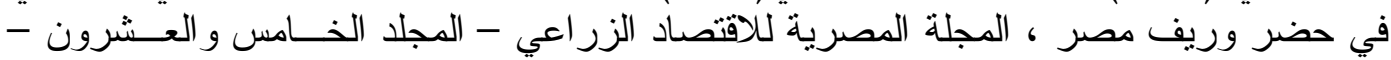

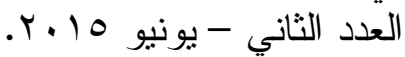

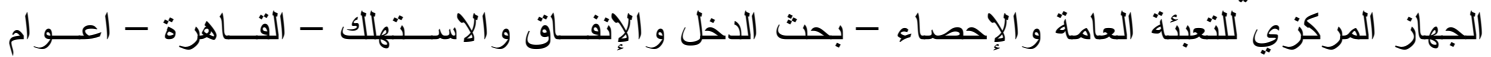

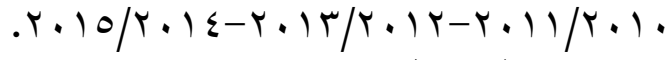

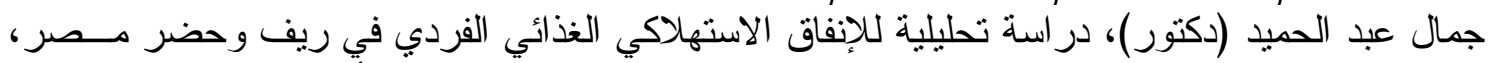

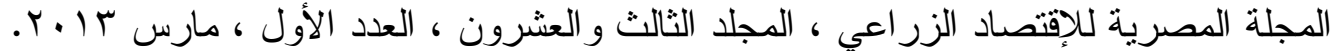




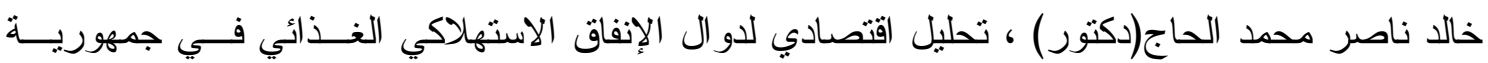

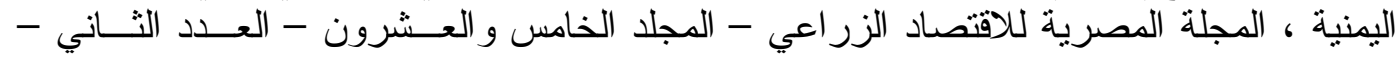

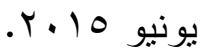

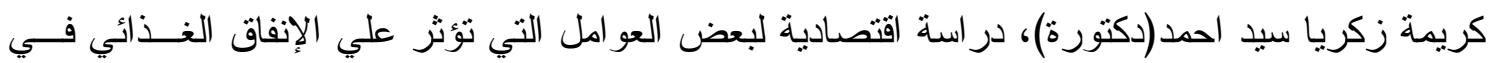

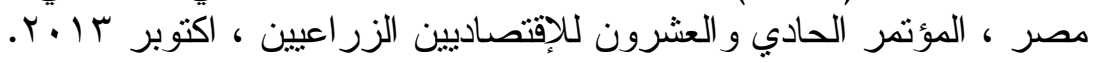

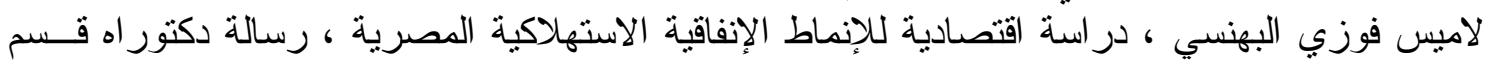

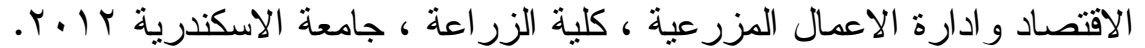

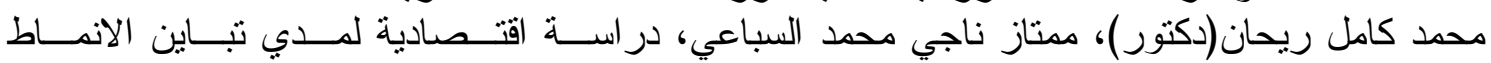

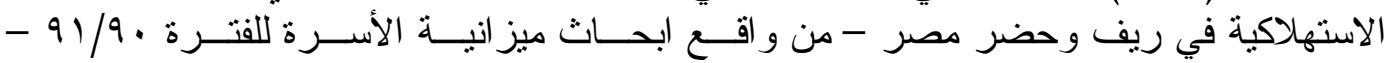

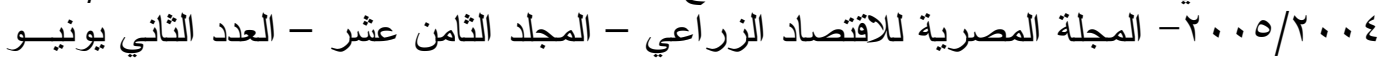
. Y.. N

محمد حافظ الماحي(دكتور)،أحمد ابو اليزيد عبد الحميد الرسول(دكتور)،الحسين عبد اللطبــف مبــروك

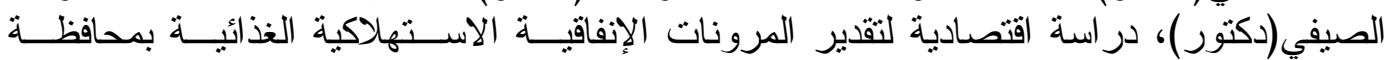

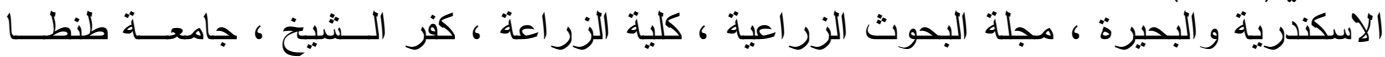
$.199 \leq$

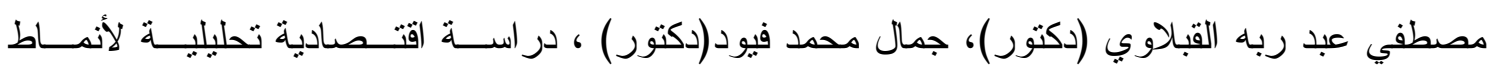

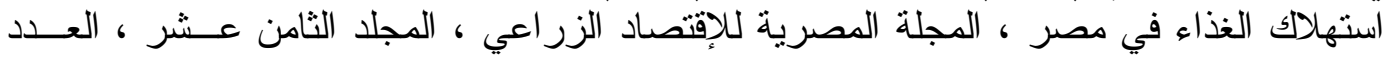

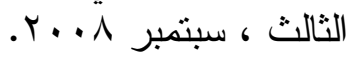

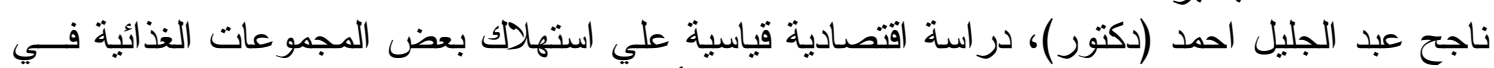

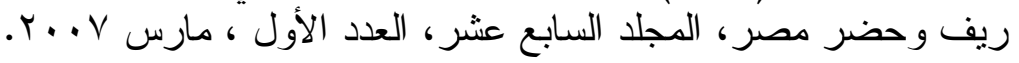




\section{Economic Study of the Patterns of Individual Consumption Spending on Different Food Groups in Rural and Egyptian}

\section{Mostafa Hassan Mohamed; Yaser Abdel-Hamed Diab and Dalia Hamed El Showeikh}

Department of Agricultural Economics, Faculty of Agriculture, Assiut University, Assiut, Egypt

\section{Abstract}

The research aims to identify changes in consumption spending patterns on the main spending groups for food and drink in urban and rural Egypt.

The research was based on descriptive and quantitative analysis using different analytical statistical criteria to study the estimate of the spending flexibility of the main commodity groups.

Also measure the effect of the difference of place and time between the two years of the study on both the average tendency of consumption and the marginal tendency of consumption and the comparison between them. As well as estimating the spending mirrors of different food commodity groups.

The most important findings of the study are as follows;

1. The relative importance of spending on food commodity groups was lower than that of non-food goods groups in Rif and Attended Egypt in 2010/11 and $2014 / 15$

2- The increase in individual and captive spending on food and drink is a spending category

3- The meat, poultry, grain and starch groups in general are the most important food commodity groups in terms of relative importance of spending, accounting for about $29.4 \%, 28.5 \%$ of the total expenditure on food commodity groups in rif and Egypt in 2010/11 respectively. In 2014/15, it was about 30.6\%, $30.5 \%$.

4- Confirming the statistical morality of the effect of the difference in spatial dimension (Rif-Hadar), which means that there are substantial and statistically moral differences in the consumption pattern of some food stuff.

By measuring the impact of temporal change during the two periods of the study, the estimated results reflected the statistically positive and moral effects of the change in the dietary consumption pattern of some groups. 